\title{
Das Römische Frauenbüchlein
}

\section{Eine Untersuchung zum Codex 200 aus Farfa}

\author{
INAUGURAL- DISSERTATION \\ zur Erlangung des Doktorgrades \\ der Medizinischen Fakultät \\ der Georg- August- Universität zu Göttingen
}

vorgelegt von

Sabine Zimmermann

aus Freudenberg

Göttingen 2012 
Dekan:

1. Berichterstatter: Prof. Dr. phil. Dr. med. habil. V. Zimmermann

2. Berichterstatter: Priv.-Doz. Dr. rer. nat. Müller

3. Berichterstatter: Prof. Dr. med. Oppermann

Tag der mündlichen Prüfung: 30. Oktober 2012 


\section{Inhaltsverzeichnis}

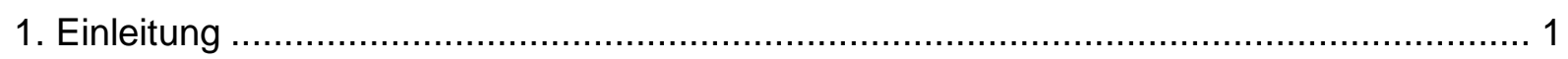

2. Über die Handschrift ..................................................................................... 4

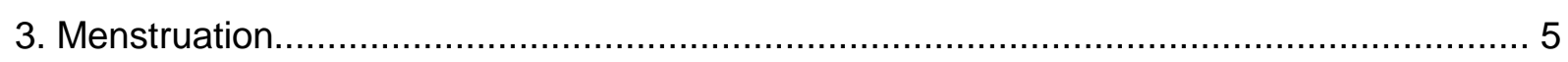

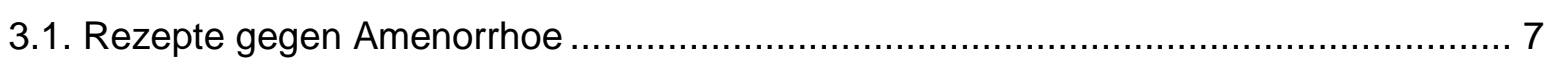

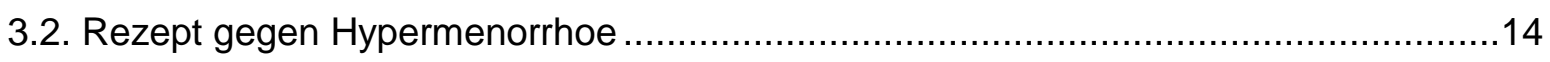

4. Der Uterus und dessen Pathologien .................................................................. 15

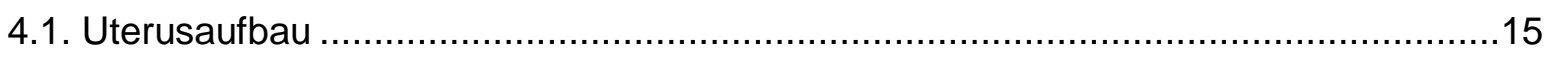

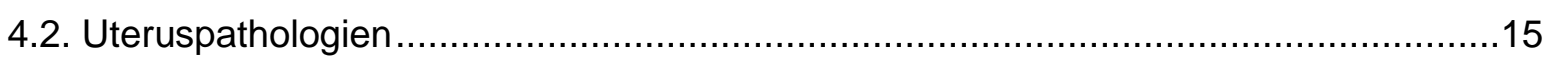

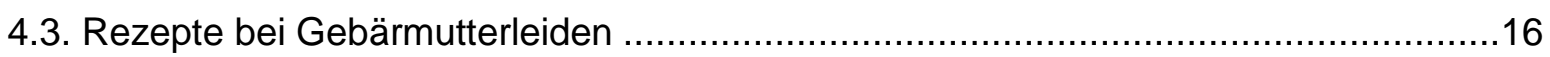

5. Die Behandlungsmethoden des äußeren Genitals..................................................26

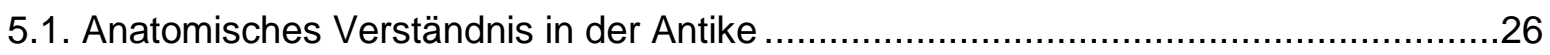

5.2. Die Krankheiten des äußeren Genitals und deren Therapie .....................................27

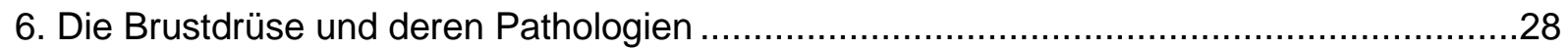

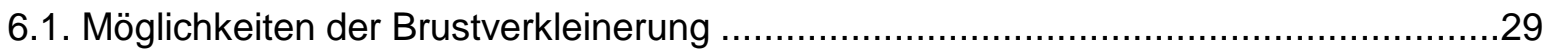

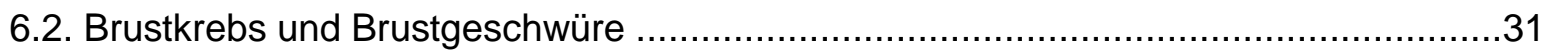

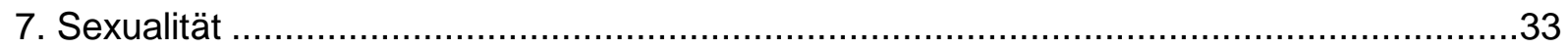

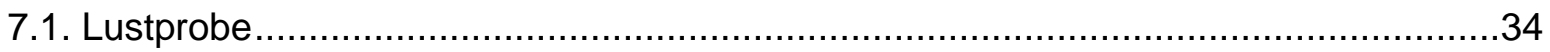

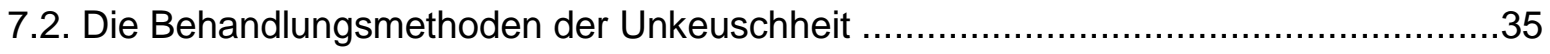

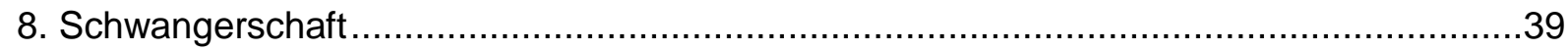

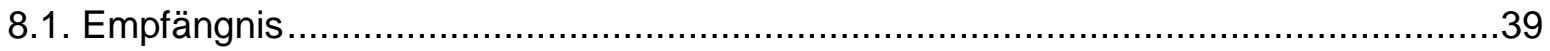

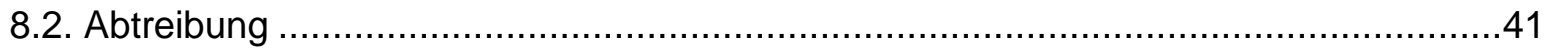

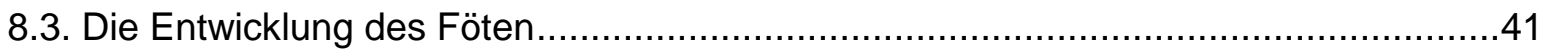

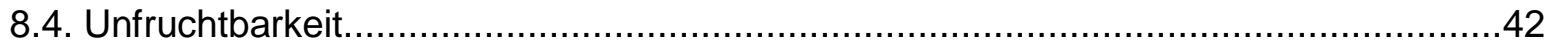

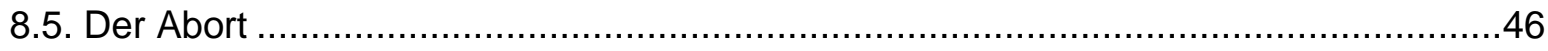

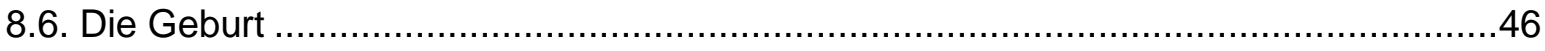

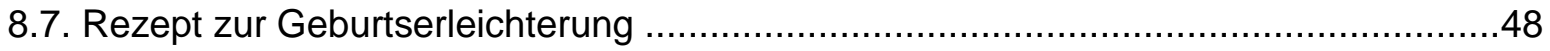

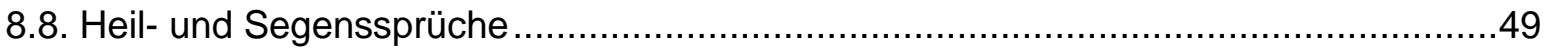

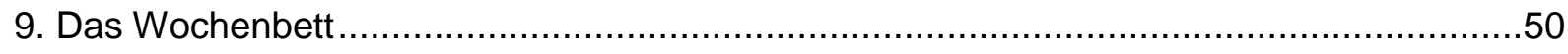

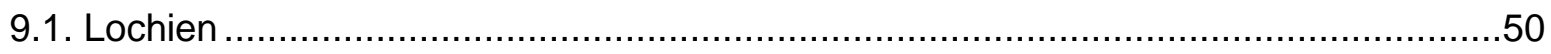

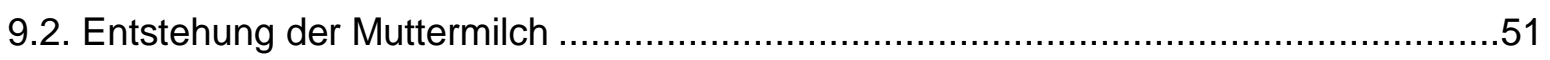

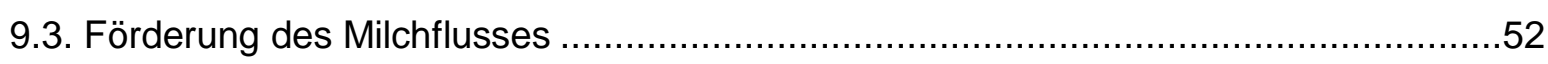


10. Grundsätze der Edition . .54

11. Edition

12. Zusammenfassung 75

13. Literaturverzeichnis 76 


\section{Rezeptliste}

Rezept Nr. $1 \quad$ (behandelt S. 6 im Text)

Rezept Nr. 2 (behandelt S. 5/6 im Text) …...................... 55

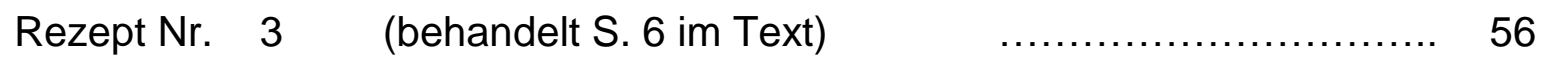

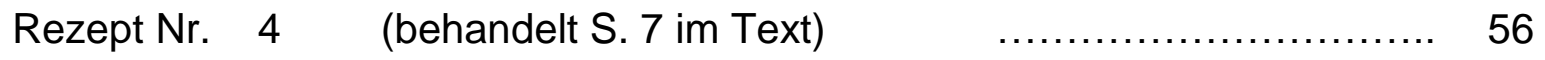

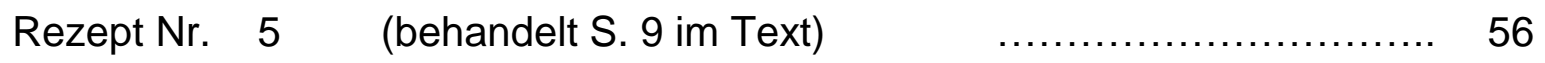

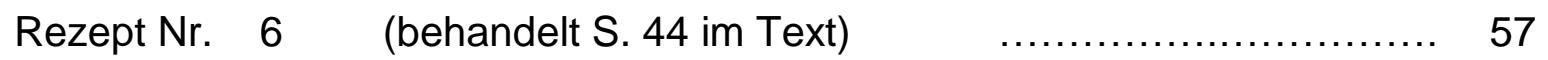

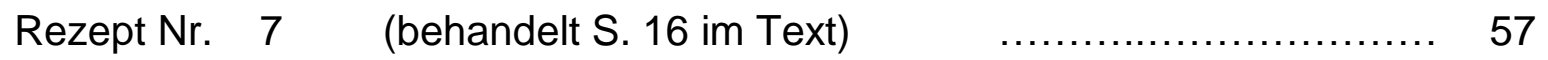

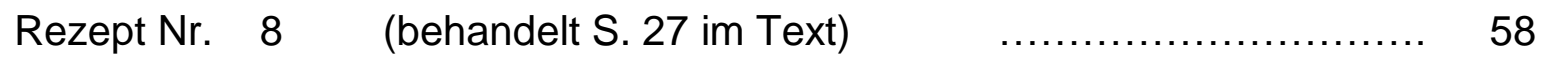

Rezept Nr. $9 \quad$ (behandelt S. $20 \mathrm{im} \mathrm{Text)} \quad$............................ 58

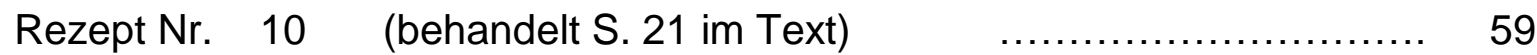

Rezept Nr. $11 \quad$ (behandelt S. 48 im Text) $\quad$........................... 59

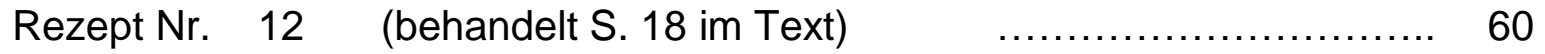

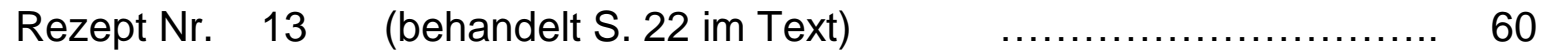

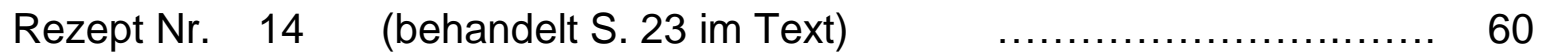

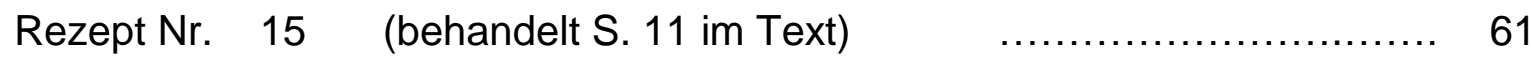

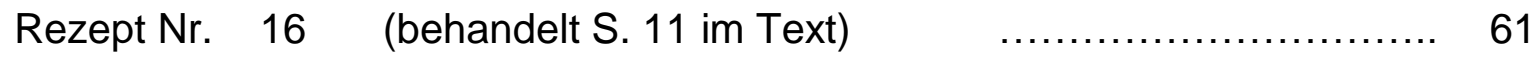

Rezept Nr. $17 \quad$ (behandelt S. 12 im Text) $\quad$.......................... 62

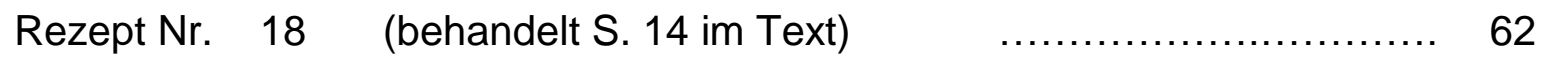

Rezept Nr. 19 (behandelt S. 42 im Text) …........................ 62

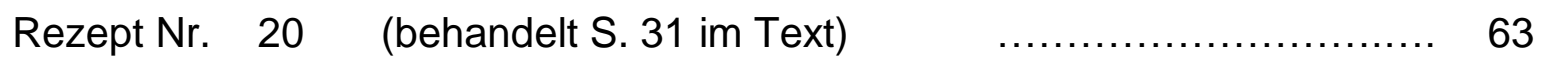

Rezept Nr. $21 \quad$ (behandelt S. 32 im Text) $\quad$......................... 64

Rezept Nr. $22 \quad$ (behandelt S. 33 im Text) $\quad$.......................... 64

Rezept Nr. $23 \quad$ (behandelt S. 52 im Text) …...................... 65 
Rezept Nr. 24 (behandelt S. 40 im Text)

Rezept Nr. 25 (behandelt S. 45 im Text)

Rezept Nr. $26 \quad$ (behandelt S. 18 im Text) 66

Rezept Nr. 27 (behandelt S. 45 im Text) 67

Rezept Nr. $28 \quad$ (behandelt S. $39 \mathrm{im}$ Text) 67

Rezept Nr. 29 (behandelt S. 45 im Text) 68

Rezept Nr. 30 (behandelt S. 47 im Text) 68

Rezept Nr. 31 (behandelt S. 42 im Text) 68

Rezept Nr. 32 (behandelt S. 44 im Text) 69

Rezept Nr. 33 (behandelt S. 40 im Text) 69

Rezept Nr. $34 \quad$ (behandelt S. 24 im Text) 69

Rezept Nr. $35 \quad$ (behandelt S. 24 im Text) 70

Rezept Nr. $36 \quad$ (behandelt S. 49 im Text) 70

Rezept Nr. 37 (behandelt S. 49 im Text) 70

Rezept Nr. $38 \quad$ (behandelt S. 50 im Text) 71

Rezept Nr. 39 (behandelt S. 46 im Text) 71

Rezept Nr. $40 \quad$ (behandelt S. 24 im Text) 71

Rezept Nr. $41 \quad$ (behandelt S. 34 im Text) 72

Rezept Nr. 42 (behandelt S. 35 im Text) 72

Rezept Nr. 43 (behandelt S. 29 im Text) 72

Rezept Nr. $44 \quad$ (behandelt S. 36 im Text) 73

Rezept Nr. $45 \quad$ (behandelt S. 37 im Text) 73

Rezept Nr. $46 \quad$ (behandelt S. 38 im Text) 73

Rezept Nr. 47 (behandelt S. 28 im Text) 74

Rezept Nr. 48 (behandelt S. 26 im Text) 74 


\section{Einleitung}

„So die muter nyder steiget, darczu nym nesseln vnd seut sie yn wasz vnd lege sie uber auf die heimliche stat"1.

Bis in das späte Mittelalter hinein waren es die Frauen selbst, die Frauenkrankheiten behandelten und Geburten begleiteten. Rezepte und Behandlungsmethoden wurden mündlich weitergegeben. In diese praktischen Rezepte flossen nach und nach aus der antiken und arabischen Medizin theoretische Erklärungen mit ein und wurden als Handschriften oder Drucke veröffentlicht. Die Kompilatoren des 15. Jahrhunderts entnahmen ihre Empfehlungen und Rezepte vermutlich aus der „Secreta mulierum“ des Pseudo- Albertus Magnus, den anonymen Schriften der „Frauengeheimnisse“ und der „Passionibus mulierum“ von Pseudo- Trotula².

Der umfangreichste editierte Text gynäkologischer mittelalterlicher Schriften stellt das „Speyrer Frauenbüchlein“ dar ${ }^{3}$. Der Wissenszuwachs um die altdeutsche gynäkologische Fachliteratur wurde durch die Zweitauflage des Verfasserlexikons deutlich erweitert. Gundolf Keil und Gerhard Eis nahmen dies vor 50 Jahren in Angriff ${ }^{4}$.

Der Codex 200 aus Farfa stellt die Grundlage dieser Arbeit her. Die gynäkologischen Rezepturen werden in einem ersten Arbeitsschritt transkribiert und daraufhin analysiert und in die einzelnen Themengebiete aufgeteilt. Der kompilativ arbeitende Verfasser der Handschrift beschrieb die einzelnen Krankheiten und deren Behandlung nicht in Reihenfolge, sondern streute sie innerhalb der gynäkologischen Rezepte immer wieder ein. Die Rezepte wurden daher in einer sinnvollen Reihenfolge den einzelnen Themengebieten zugeordnet und in der Arbeit zu den jeweiligen Krankheiten aufgeführt. $\mathrm{Zu}$ folgenden gynäkologischen Themen finden sich Rezepte und Behandlungsmethoden in der Handschrift:

- Menstruationsstörungen

- Erkrankungen des Uterus

\footnotetext{
${ }^{1}$ vgl. Rezept Nr. 35, S. 66

${ }^{2}$ vgl. Kruse, 1996, S. 1- 4

${ }^{3}$ vgl. Siegmund, 1990

${ }^{4}$ vgl. Kotsch/ Keil, 2008/ 09, S. 47- 48
} 
- äußeres Genital

- Brüste

- Sexualität

- Schwangerschaft

- Wochenbett.

Die Behandlungen der Menstruationsstörungen umfassen die Amenorrhoe, hier wird ein großer Teil abortivwirkender Pflanzen gefunden. Ein Text zur Behandlung der Hypermenorrhoe wird beschrieben. Ein großer Abschnitt im Codex nimmt die Behandlung der Pathologien des Uterus ein. Einige Rezepte beschreiben die damalige Hysterietherapie. Jedoch wird auch auf die Therapie eines Geschwürs oder Karzinoms eingegangen. Die Krankheiten des äußeren Genitals beschränken sich auf die Entzündung und deren Behandlung.

Dem Schönheitsideal des Mittelalters entsprechend, wird bei der Behandlung der Brustdrüse auf die Verkleinerung der Brüste eingegangen. Die Texte zur Behandlung der Brustgeschwüre und Karzinome finden innerhalb des Codex Erwähnung.

Zum Themenbereich Sexualität beschreibt der Kompilator eine Lustprobe, weitere Rezepte umfassen die Behandlung der Unkeuschheit.

Auf die Empfängnis bis zur Schwangerschaft, mitsamt den Pathologien in diesem Bereich, wird im Codex eingegangen. Behandlungsmethoden, Heil- und Segenssprüche finden Erwähnung. Dem Wochenbett wird lediglich ein Rezept gewidmet, dies umfasst das Stillen.

Bei der Bearbeitung der Handschrift wird deutlich, dass der kompilativ arbeitende Verfasser über ein spärliches medizinisches Wissen verfügte. Im Vergleich zu anderen Codices fehlen teilweise die Interpretationen der Befunde. Auf das Heranziehen diagnostischer Möglichkeiten, wie beispielsweise einer Katamanienschau, wird gänzlich verzichtet. Auf Mengenangaben wird weitestgehend nicht eingegangen, oder wenn diese aufgenommen wurden standen sie in keinem logischen Kontext zu dem Rezept. Invasive Behandlungsmöglichkeiten, wie die eines 
Aderlasses, finden keinerlei Erwähnung. Es ist davon auszugehen, dass sich die Rezepturen an Laienärzte richteten, oder an die Frauen selbst und weitgehend auf Emperie beruhen.

Einige Themenbereiche fehlen in der Handschrift vollkommen, wie beispielsweise die Geschlechtsprobe des Ungeborenen und das Ausbleiben der Nachgeburt. Die Entbindung wird ebenfalls nicht umfangreich beschrieben. Zur Geburtserleichterung finden sich lediglich Segenssprüche, pflanzliche Drogen werden in diesem Bereich keineswegs erwähnt, nur die Verwendung von Mineralien wird aufgenommen. Das Wochenbett scheint dem Kompilator ebenfalls nicht sehr wichtig zu erscheinen, findet sich doch nur ein Rezept zur Förderung des Milchflusses, während auf die Frau und deren Beschwerden nach einer Entbindung nicht eingegangen wird. Der Lochialfluss und eventueller Lochialstau, sowie die Mastitis bei Stillenden, scheinen dem Kompilator nicht erwähnenswert zu sein.

Ziel der Arbeit ist es, die einzelnen pflanzlichen Bestandteile in ihrer Wirkung zu beschreiben und diese mit der im Text genannten Indikation zu vergleichen. Ebenfalls sollen heutige noch in der Gynäkologie und Geburtshilfe gebrauchte pflanzliche Wirkstoffe gefunden werden. Als weiteres soll versucht werden, die beschriebenen Krankheiten im Codex mit den heute bekannten Erkrankungen zu vergleichen.

Parallelen zu anderen Codices sollen, wenn vorhanden, aufgezeigt werden. 


\section{2. Über die Handschrift}

Die Handschrift Codex 200 aus dem Benediktinerkloster Farfa in Latium, wurde im Jahre MCCCCLX durch einen anonymen Kompilator verfasst. Es wird angenommen, dass der Kompilator ein deutscher Mönch gewesen sei, der dem Orden der Benediktiner angehörte. Die Vermutung über die Nationalität geht daraus hervor, dass der Kodex überwiegend deutschsprachige Schriften aufweist, von einigen italienischen Einsprengseln abgesehen.

Nachträgliche Eintragungen in der Handschrift lassen erkennen, dass diese um 1500 im Besitz des Mönches Michael Schwirker gewesen sein muss.

Die Handschrift umfasst insgesamt 230 Blätter, die Schrift enthält wenig Korrekturen und entspricht einer schwäbisch- bairischen Bastarda aus dem späten 15. Jahrhundert. „Der Text ist ganzseitig angeordnet. Der Schriftspiegel ist vorgezeichnet, er wird im großen und ganzen streng eingehalten. Der Schreibraum besteht in der Regel aus 38 Zeilen; davon sind 36 beschrieben“" ${ }^{5}$. Eine alte nicht korrekte Zählung wurde verbessert.

Die Handschrift besteht zum größten Teil aus heilkundlichen Texten und Arzneibüchern, hierunter befinden sich Schriften bekannter Autoren, wie zum Beispiel das Werk des Thüringer Bartholomäus oder ein Wundrezept von Peter von Abano. Neben den Arzneibüchern existieren zum Teil umfangreiche Rezeptsammlungen, die der mittelalterlichen Gliederung " a capite ad calcem" nicht entsprechen ${ }^{6}$.

Innerhalb der Rezeptsammlungen finden sich Passagen zur Heilung bestimmter Krankheiten, auch die Texte zu dieser Arbeit. Auf Blatt $171 \mathrm{r}$ beginnen die gynäkologischen Rezepturen und enden auf Blatt 175r.

\footnotetext{
${ }^{5}$ Zimmermann, 1986, S. 14

${ }^{6}$ vgl. Zimmermann, 1986, S. $14-16$
} 


\section{Menstruation}

In ihrer Bedeutung wurde die Menstruation im Mittelalter von verschiedenen Seiten aus betrachtet und bewertet. Unter humoralpathologischen Gesichtspunkten war die Menstruation ein Ausdruck der weiblichen anatomischen Konstitution, die aus dem natürlichen Überhang der Säfte resultierte und somit ein Zeichen der Reinigung und des natürlichen Aderlasses darstellte. Ferner war das Menstrualblut im Falle einer Schwangerschaft für die Ernährung des Embryos beziehungsweise des Feten verantwortlich ${ }^{7}$.

Hippokrates beschrieb, dass sich das weibliche Gewebe mit Flüssigkeit vollsaugt und die Menstruation diesen Überschuss reguliert, um den weiblichen Körper im Gleichgewicht zu halten. Eine Amenorrhoe sorgt für einen Verlust der Balance, die Frau wird krank und zeigt Symptome wie Frösteln, Fieber, Rückenschmerzen, schleimiges Erbrechen, blutigen Urin und sogar ihr Tod wird als Folge beschrieben ${ }^{8}$.

Bei Hildegard von Bingen, wurde die Menstruation ebenfalls als Reinigung des Körpers angesehen. So mischte sich das Blut der Frau mit ihren gebrechlichen Säften, um aus den Gefäßen der Lenden auszutreten. Die Ursache einer Amenorrhoe war die traurige Stimmung der Frau. Ihre Gemütslage sorgte dafür, dass der Säfteüberschuss eine verkehrte Wärme erzeugte und die monatsblutführenden Gefäße austrocknete $^{9}$. Zu Beginn der Menstruation werden bei der Frau die Organe geöffnet, die den männlichen Samen empfangen. Infolge dessen wurde auch das Konzeptionsoptimum zu dieser Zeit gesehen ${ }^{10}$. Wenn die Frau zu diesem Zeitpunkt unter großem Lustgewinn den männlichen Samen empfängt, schließen sich ihre Organe und behalten den Samen. "Daraufhin durchmischt das Monatsblut den Samen, macht inn blutartig und fleischt inn ein"11. Der Kompliator der Handschrift beschreibt im Rezept Nr. 2 (S. 55) „so daz weib somen enphet“, die Menstruation als Teil der Empfängnis. Der Frau stockt das Blut, wenn sie den Samen des Mannes empfangen habe. Für Aristoteles diente das Menstruationsblut als weiblicher Samen, es wird jedoch als weitaus weniger wertvoll erachtet. Es wurde ebenso, wie die

\footnotetext{
${ }^{7}$ vgl. Fischer- Homberger, 1988, S. 35

${ }^{8}$ vgl. Fischer-Homberger, 1988, S. 34

${ }^{9}$ vgl. von Bingen, 1957, S. 180

${ }^{10}$ vgl. von Bingen, 1957, S.176/ 177

${ }^{11}$ von Bingen, 1957, S. 178
} 
weibliche Konstitution, als kalt bezeichnet, welches sich, allein seiner Farbe wegen, von dem Samen des Mannes unterschied. Die Erklärung lag in der körperlichen Herstellung des Samens, so wurde der männliche Samen durch die Verbindung der Venen zu den Samenkanälen in eine Reinform gebracht und durch die Nahrung gestärkt. Der Kompilator der Handschrift beschreibt diesen Vorgang im Rezept Nr.1 (S. 55) „von dem menschlichen Somen“. Demnach sollte vom Magen aus die Nahrung über die Adern in die Lenden gelangen, um den Samen zu vervollständigen. Auch die Abstammung des Menschen durch den männlichen Samen wird hier beschrieben. Bei der Frau waren die Leber und die Venen unfähig, die Nahrung zu verwerten und sie mit dem Samen zu verbinden. Somit lieferte der weibliche Samen nur die Materie, aus der das Kind gebildet wurde, der Rest wurde durch den Mann gegeben. Die Erzeugung eines Kindes wurde mit dem Ackerbau verglichen. Der Mann war der Bauer, dem die Frucht des Feldes gehörte, er bestimmte, was wächst, und bestimmte Name, Art und Aussehen. Eine erfolgreiche Zeugung war die Erschaffung eines einfachen Doppels des Vaters, also die eines Jungen. Wurde der schöpferische Impuls des Mannes durch das schlechte Menstrualblut gestört, entstand ein Mädchen ${ }^{12}$.

Die Beschreibung des Menstruationsblutes als Gift und Gegenstand der Verunreinigung findet sich in 3. Buch Mose, Kapitel 15, in dem Gesetz über das Verhalten bei unreinen Ausflüssen. „Wenn eine Frau ihren Blutfluß hat, so soll sie sieben Tage für unrein gelten. Wer sie anrührt, der wird unrein bis zum Abend“"13.

In der Naturgeschichte von Plinius werden Früchte an Bäumen faul und Eisen stumpf, wenn sie in Kontakt mit Menstruationsblut kommen. Hunde, die das Blut fressen, werden unsinnig. Dies wird auch im Rezept Nr. 3 (S. 56) beschrieben: Das Blut der nicht schwangeren Frau führt dazu, dass Hunde, die das Blut essen würden, wütend werden. Kein Leim sei so stark wie das Menstruationsblut. Wasser und Eisen könnten durch das Blut getrennt werden und ein Tropfen davon ließe alles vergehen.

Durch böse Dämpfe, die während der Menstruation in den Kopf der Frau stiegen, würden Spiegel durch ihre Blicke trüb ${ }^{14}$. Der Kompilator der Handschrift weist im

\footnotetext{
${ }^{12}$ vgl.Fischer- Homberger, 1988, S. 36- 37

13 3. Mose 15, Vers 19, (Die Bibel 1985)

${ }^{14}$ vgl. Fischer-Homberger, 1988, S. 41- 42
} 
Rezept Nr. 2 (S. 55) darauf hin, dass das Menstrualblut böse und schrecklich sei und einem Mann schadet, er dörre davon aus wie auch Kraut und Baumrinden trocknen.

Die Menarche wurde allgemein zwischen dem dreizehnten und sechzehnten Lebensjahr beschrieben. Mädchen waren bis zu diesem Zeitpunkt heißer Natur und daher genauso wie die Männer imstande, überschüssige schädliche Säfte zu verbrennen. Die Länge des Zyklus wurde durch den Mond und das Temperament der Frau beeinflusst ${ }^{15}$. Im Bereich der hippokratischen gynäkologischen Diagnostik, wurden die Farbe und die Beimengungen des Menstrualblutes beurteilt und somit auf eine Dyskrasie zurück geschlossen ${ }^{16}$. Hildegard von Bingen datiert das Klimakterium zwischen dem fünfzigsten und sechzigsten Lebensjahr einer Frau, zu diesem Zeitpunkt verschließen sich ihre fensterähnlichen Organe und trocknen aus, die Gebärmutter schrumpft und die Frau kann keine weiteren Kinder mehr bekommen ${ }^{17}$.

\subsection{Rezepte gegen Amenorrhoe}

Im Rezept Nr. 4 (S. 56) findet sich eine Rezeptur gegen die Amenorrhoe. Um die Menstruation auszulösen, empfiehlt der Verfasser Salbei ${ }^{18}$, Rauten, Wermutzweige und Sadebaum miteinander in einem Topf zu kochen und den Dampf an die Scham gehen zu lassen.

Der als Salvia officinalis L. bezeichnete Salbei enthält bakterizide Inhaltsstoffe, das ätherische Öl im Salbei enthält, wie auch der Wermut, Thujon in einem Anteil von 40$60 \%$. Salbei war heißer und trockener Natur, er wirkt stimulierend, bakterizid, wundheilend und wurde als Magenmittel verwendet ${ }^{19}$. Der Salbeiwein wurde zur Antikonzeption angewendet. Diesen nahmen die Frauen nach dem Beischlaf ein, um eine Befruchtung zu vermeiden. Die Wirkung konnte, durch seine kalte Eigenschaft,

\footnotetext{
${ }^{15}$ vgl. Kruse, 1996, S.220- 221

${ }^{16} \mathrm{vgl}$. Diepgen, 1937, S. 240

${ }^{17}$ vgl. von Bingen, 1957, S. 180

18 „Salfen“ werden in Salbei übersetzt, da dieser eine logische Ergänzung zu den beschriebenen Pflanzen darstellt und in mehreren Rezeptsammlungen mit diesen zu finden ist.

${ }^{19}$ vgl. Mildenberger, 1997, S. 1649
} 
bis zu einem Jahr anhalten ${ }^{20}$. Möglicherweise war es nicht nur die bakterizide, wundheilende Eigenschaft des Salbeis, die der Kompilator beabsichtigte, sondern auch die antikonzeptionelle Wirkung, um den Uterus als Organ zu schonen. Eine auf die Milchdrüse hemmende Eigenschaft war ebenfalls bekannt ${ }^{21}$.

Im Mittelalter zählten der Sadebaum und die Raute zu den wichtigsten Emmenagoga, jedoch fanden sie auch als Abortivum Anwendung. Diese Pflanzen galten als warm und trocken und sollten den kalten und feuchten Körper der Frau therapieren ${ }^{22}$. „Die in diesen Pflanzen enthaltenen ätherischen Öle bewirken einen Blutdrang im Becken und provozieren damit den Eintritt der Menstruation“23. Mattioli spricht in seinem Arzneibuch gegenüber dem Sadebaum eine eindeutige Warnung aus. Er empfiehlt eine strenge Kontrolle des Handels mit dieser Pflanze, sicherlich mit dem Wissen darum, dass dieser als Abortivum eine sehr gute Wirkung erzielte ${ }^{24}$. „Der Sadebaum, Juniperus Sabina, gehört zu den Nadelhölzern (Zypressenfamilie) und ist ein liegender oder aufrechter, stark verzweigter Strauch (seltener ein kleiner Baum) mit zuerst nadelförmigen, später schuppenartigen Blättern“25. Die offizielle Erklärung für das Vorhandensein eines Sadebaums im Hausgarten war, dass die jungen Damen daraus eine Arznei zubereiteten, um eine mangelhafte oder ausgebliebene Menstruation zu fördern. Dioskurides erwähnte diese Pflanze unter verschiedenen Synonymen, in Griechenland war sie als sabinisches Kraut bekannt. In seinem Werk „De materia medica“ sollten die Blätter bei Geschwüren und Entzündungen verwendet werden. Innerlich angewendet und mit Wein getrunken trieb die Pflanze Blut mit dem Urin und auch den Fetus aus. Vaginal eingeführt oder als Räucherung erzielte sie dieselbe Wirkung. Neben den Blättern wurden auch die Gipfeltriebe verwendet. Beide enthalten Pinipicrin, ein Glycosid. Weiter finden sich Gerbstoffe, Harz, Kalksalze und ein unangenehm riechendes ätherisches Öl, welches Sabinol, Sabinolacetat und L-Sabinol enthält und die Wirkung des Sadebaums ausmacht. Wurden zu hohe Dosen der wirksamen Bestandteile

\footnotetext{
${ }^{20}$ vgl. Kruse, 1996, S. $170-171$

${ }^{21} \mathrm{vgl}$. Dragendorff, 1967, S. 57

${ }^{22}$ vgl. Kruse, 1996, S.174- 175

${ }^{23}$ Kruse, 1996, S. 175- 176

${ }^{24}$ vgl. Mattioli,1594- 1615, S. 32vD

${ }^{25}$ Brøndegaard, 1964, S.332
} 
eingenommen, konnte dies zur Vergiftung führen, welche nicht selten letal für Mutter und Fetus endete ${ }^{26}$.

Die Weinraute, Ruta graveolens L., wurde in Nordafrika und Südeuropa oft kultiviert. Das frische Kraut wurde innerlich angewendet und löste einen Abort aus. Das getrocknete Kraut besaß spasmolytische Wirkung und diente als Wurmmittel, Antisepticum, Emmenagogum sowie zur Sedierung. Auch schweißtreibende Eigenschaften wurden beschrieben. Zur Ruta graveolens zugehörig sind auch Ruta divaricata Tenore und Ruta montana Mill., welche in ihrer Wirkung stärker als die Weinraute selbst waren. Die Raute enthält ätherisches Öl mit Pelargon-, Caprin- und Methylcaprinsäure, außerdem Cumarin und Rutin ${ }^{27}$.

Der auch als Artemisia Absinthium L. bezeichnete Wermut, der ebenfalls ätherische Öle enthält, könnte den Blutdrang im Becken weiter unterstützt haben ${ }^{28}$. Er wird als bitter und scharf beschrieben, wirkt zusammenziehend, wärmend, säubernd und stärkend $^{29}$. Diese beschriebene Wirkungsweise könnte genutzt worden sein, um einen übermäßigen Blutfluss zu verhindern und somit die Frau bei Kräften zu halten. Die im zentralen Nervensystem angreifende Wirkung des Wermuts beruht auf dem enthaltenen Thujon, es könnte als schmerzstillendes Mittel Verwendung gefunden haben $^{30}$.

Das Rezept Nr. 5 (S. 56) enthält ebenfalls einen Traktat über die Menstruationsförderung. Hier wird Myrre mit Beifußsaft und Hirschhorn empfohlen, diese sollen entzündet und als Räucherung appliziert werden, indem sich die Frau verhüllt und über den Rauch stellt. Eine schnelle Wirkung wird versprochen, jedoch soll sie, um die Menstruation zu lösen, Raute essen und Wermutsaft trinken und auch dessen Wurzel unter die Beine legen.

\footnotetext{
${ }^{26}$ vgl. Brøndegaard, 1964, S. 331- 337

${ }^{27}$ vgl. Dragendorff, 1967, S. 351- 352

${ }^{28}$ vgl. Dragendorff, 1967 S. 677

${ }^{29}$ vgl. Mattioli,1594- 1615, S. 233vD

${ }^{30}$ vgl. Mildenberger, 1997, S. 2280
} 
Die Myrre galt als warm und trocken ${ }^{31}$ und wurde als Räuchermittel verwendet ${ }^{32}$. Bei den Griechen wurde inr eine adstringierende und hypnotische Wirkung zugesprochen, später fand die Myrre als Antiseptikum bei eiternden Wunden Anwendung ${ }^{33}$.

Der Beifuß, in der botanischen Gruppe als Artemisia vulgaris L. zu finden, wurde unter anderem zur Behandlung von Nerven- und Geschlechtskrankheiten eingesetzt ${ }^{34}$. Seine Eigenschaften waren trocken und durchdringend ${ }^{35}$. Äußerlich angewendet, reinigte er die Gebärmutter, in der Verbindung mit Myrre zog er die Feuchtigkeit aus dem Uterus ${ }^{36}$. Beifuß existiert in zweierlei Farbvarianten, diesen Unterschied machte man sich zu Nutze, um die Frequenz und Intensität der Menstruation zu regulieren ${ }^{37}$.

Das Hirschhorn ist keratinhaltig, durch das Erhitzen entsteht Hirschhornsalz ${ }^{38}$. Das nach dem Verbrennen entstandene Pulver wurde zur Blutstillung verwendet ${ }^{39}$. Hirschhorn half gegen Gebärmutterschmerzen und bei Hypermenorrhoe. Zur Hysterietherapie bei Uterusbewegung wurde es ebenfalls verwendet ${ }^{40}$. Der Kompilator wollte vermutlich mit der Verwendung des Hirschhorns einem zu großen Blutverlust entgegenwirken.

Eine weitere Möglichkeit der Scheidenräucherung stellte der Schemel dar, dieser findet im Rezept keine Erwähnung. Er war in der Mitte gelöchert und unter inm wurde auf einem Kohlebecken der Arzneistoff verbrannt. Um eine möglichst hohe Konzentration des Wirkstoffes zu erreichen, diente der Rock der Frau als eine Art Zelt, welches sich um den Schemel herum aufspannte ${ }^{41}$. Eine weitere Form der Räucherung bestand darin, einen mit Wasser gefüllten Topf, in dem die Arzneistoffe enthalten waren, zu erhitzen und den Dampf an die Scham zu leiten. Jegliche Formen der Räucherung erfüllten den Zweck, die Arzneistoffe in die Scham dringen

\footnotetext{
${ }^{31}$ vgl. Mattioli, 1594- 1615, S. 20vC

${ }^{32} \mathrm{vgl}$. Dragendorff, 1967, S. 367

${ }^{33}$ vgl. Dragendorff, 1967, S. 367

${ }^{34}$ vgl. Dragendorff, 1967, S. 680

${ }^{35}$ vgl. Mattioli, 1594- 1615, S. 295vC

${ }^{36}$ vgl. Mattioli, 1594- 1615, S. $295 \mathrm{vD}$

${ }^{37}$ vgl. Kotsch/ Keil, 2008/09, S.72

${ }^{38}$ vgl. Mildenberger, 1997, S. 837

${ }^{39}$ vgl. Rohland, 1982, S. 103

${ }^{40} \mathrm{vgl}$. Jühling, 1900, S. 62- 64

${ }^{41}$ vgl. Kotsch/ Keil, 2008/09, S. 54
} 
zu lassen, um eine mit Blut verstopfte Gebärmutter zu reinigen oder die Gebärmutter zu öffnen, um den männlichen Samen zu empfangen ${ }^{42}$.

Der Wermut und die Raute mit entsprechender Wirkung wurden bereits im Rezept Nr. 4 beschrieben.

Im Rezept Nr. 15 (S. 61) wird empfohlen, Weinrebenasche in ein Tuch zu geben und dieses an die Scham zu legen, um die Menstruation herbeizuführen.

Weinranken wirken adstringierend ${ }^{43}$. Allgemein wurde der Asche eine besonders wirksame Heilkraft zugesprochen, da die Überreste der Verbrennung frei vom dämonischen Stoff seien. Die Aschenlauge galt als reinigendes, die Haut von Schmutz befreiendes Mittel ${ }^{44}$.

Die Temperatur des eigenen Körpers wurde durch das Auflegen der Arznei auf die Haut, ähnlich einem Umschlag, genutzt, um eine Verstärkung der Arzneimittelwirkung zu erzielen ${ }^{45}$.

Im Rezept Nr. 16 (S. 61) "daz den weiben ir recht chume“, wird Eibischwurzel in Wasser gesiedet, der Dampf dient der Räucherung der Scham. Um das sofortige Eintreten der Menstruation zu garantieren, soll die Frau zusätzlich Raute und Eisenkraut essen. Eine weitere Möglichkeit, die von dem Kompilator genannt wird, ist das Trinken von Bachminzensaft, oder diesen auf einen heißen Stein zu geben und über einen Trichter den dabei entstehenden Rauch an die Scham gehen zu lassen. Dadurch soll die Menstruation ebenfalls sofort eintreten.

Der Eibisch, Althaea officinalis L., wirkt schleimbildend ${ }^{46}$. Die Eibischwurzel wirkte austreibend auf den Uterus, ebenso auf die Plazenta, wenn sie nach der Geburt im

\footnotetext{
${ }^{42}$ vgl. Kruse, 1996, S. 87

${ }^{43}$ vgl. Dragendorff, 1967, S.415

${ }^{44}$ vgl. HWdA, 1927, Band I, Sp. 611

${ }^{45}$ vgl. Kruse, 1996, S. 82
} 
Mutterleib geblieben war ${ }^{47}$. Daher könnte dieses Rezept auch in der Geburtshilfe Anwendung gefunden haben. Äußerlich angewendet besitzt sie entzündungshemmende und kühlende Eigenschaften ${ }^{48}$.

Die Anwendung der Raute und deren Wirkung wurde im Rezept Nr. 4 bereits beschrieben.

Das Eisenkraut, Verbena officinalis L., wurde als heilige Pflanze und Zaubermittel verwendet. Heute wird sie zur Fiebersenkung eingesetzt ${ }^{49}$. Eisenkraut war warmer wie auch kalter Natur, es heilte Wunden und zog das Fleisch zusammen ${ }^{50}$.

Bachminze besitzt eine geringe zusammenziehende Wirkung ${ }^{51}$. Die Mentha aquatica L. enthält ätherische Öle und wurde gegen Koliken und Asthma empfohlen ${ }^{52}$. Sie ist der Mentha piperita Smith, der Pfefferminze ähnlich, diese besitzt eine spasmolytische und belebende Wirkung ${ }^{53}$.

Die Applikationsform der Räucherung wurde bereits im Rezept Nr. 5 beschrieben.

In dem Rezept Nr. 17 (S. 62) empfiehlt der Kompilator, bei einer Amenorrhoe Spitzwegerich, Kümmel, Hafer und Nesseln zu zerstoßen und diese mit Gerstenmehl zu vermischen. Diese Mischung soll warm an die Scham gelegt werden. Als Alternative wird die Verwendung eines abgeschlagenen rechten Maulwurffußes genannt, diese soll dem lebendigen Tier abgeschlagen und drei Bluttropfen des Tieres sollen an drei Tagen morgens nüchtern eingenommen werden. Wenn die Menstruation durch diese Methode nicht eintritt, werde die Frau sterben.

Von den Plantaginaceae sind circa 250 Arten bekannt. Die Wegericharten enthalten auf ihrer Samenoberfläche Schleimzellen. Als Mucilaginosum fand der Wegerich innerliche Anwendung gegen Ruhr, Diarrhoe und Harnkrankheiten. Äußerlich wurde

\footnotetext{
${ }^{46}$ vgl. Dragendorff, 1967, S. 422

${ }^{47}$ vgl. Mattioli, 1594- 1615, S. 136vC

${ }^{48}$ vgl. Mattioli, 1594- 1615, S. 136vD

${ }^{49}$ vgl. Dragendorff, 1967, S.564

${ }^{50}$ vgl. Mildenberger, 1997, S. 924,

${ }^{51}$ vgl. Mattioli, 1594- 1615, S. 245rB

${ }^{52}$ vgl. Dragendorff, 1967, S. 583

${ }^{53}$ vgl. Dragendorff, 1967, S. 583
} 
er bei Geschwülsten und Entzündungen verwendet ${ }^{54}$. Der Saft des Spitz- oder Kleinwegerich, auch Plantago minor genannt, wurde als Gichtmittel und bei mancherlei Blasenleiden eingesetzt. Das Kraut wurde unter anderem zum Lösen der Nachgeburt (Plazenta) eingesetzt. Die Blätter wurden beispielsweise bei Organbeschwerden auf der Haut über dem Organ selbst oder oberhalb der Milz aufgelegt ${ }^{55}$.

Der Kümmel besitzt wärmende und öffnend- treibende Eigenschaften. Äußerlich angewendet heilte er Geschwülste an den Genitalien und half bei langanhaltendender Monatsblutung ${ }^{56}$. Er könnte in diesem Rezept Anwendung gefunden haben, um ein Übermaß an Blutung zu vermeiden. Der als Carum Carvi L. bezeichnete Kümmel enthält ätherisches Öl, Carvol und Carven als Wirkstoffe. Er besitzt spasmolytische Eigenschaften und wurde bei Magen-Darm Leiden eingesetz $\mathrm{t}^{57}$.

Hafer wirkt austrocknend und stopfend ${ }^{58}$. Innerlich mit dem Essen aufgenommen, war er warmer Natur, äußerlich angewendet wirkte er kühlend und austrocknend auf Geschwüre und Fisteln. Er galt als natürliches Schönheitsmittel. Der Samen und das Kraut des Hafers wurden zur Stillung der Diarrhoe eingesetzt, er wirkte diuretisch und säubernd auf die Blase und den Uterus ${ }^{59}$.

Von den Nesseln gibt es ca. 520 Arten. Hauptsächlich in Europa zu finden ist die Brennnessel, auch Urtica dioica L. genannt, sie wird medizinisch gegen Blutungen, Diarrhoe und Hämorrhoiden eingesetzt. Die Urtica balearica L. wirkt galaktogen. Bei der Urtica membranacea Poir. wirken die Samen und das Kraut als Emmenagogum und Aphrodisiakum. Alle diese Nesseln besitzen Brennhaare, in denen Ameisensäure $\mathrm{zu}$ finden ist ${ }^{60}$. In dem Arzneibuch von Mattioli wird die Hypermenorrhoe durch die Einnahme destillierter Eiternessel (Eyternessel) gestoppt. Äußerlich angewendet half die Nessel bei Nekrosen und Krebsleiden ${ }^{61}$.

\footnotetext{
${ }^{54}$ vgl. Dragendorff, 1967, S. 618

${ }^{55}$ vgl. Lonicerus, 1679, S. 322

${ }^{56}$ vgl. Mattioli, 1594- 1615, S. 264rB

${ }^{57}$ vgl. Dragendorff, 1967, S. 488

${ }^{58}$ vgl. Mattioli, 1594- 1615, S. $108 \mathrm{vD}$

${ }^{59}$ vgl. Lonicerus, 1679, S. 525- 526

${ }^{60} \mathrm{vgl}$. Dragendorff, 1967, S. 179

${ }^{61}$ vgl. Mattioli, 1594- 1615, S. 396rA
} 
Die Gerste war kalt und trocken im ersten Grad, sie säubert und öffnet. Innerlich angewendet mit Fenchel und Pfeffer wirkte sie galaktogen, äußerlich angewendet heilte sie Geschwüre ${ }^{62}$. Der Samen der Gerste wird zu Mehl verarbeitet ${ }^{63}$. Das Gerstenmehl in diesem Rezept könnte als Trägersubstanz für die pflanzlichen Wirkstoffe gedient haben, warm aufgelegt könnte es deren Wirkung verstärkt haben.

Der Maulwurf galt seit Plinius als Teufels- und Hexentier. Schwangere Frauen sollten einen Maulwurf nicht töten oder gar anschauen. Das Maulwurfblut sollte vor Behexung schützen, der Verzehr seines Herzens verlieh einem Menschen die Wahrsagekunst. Die Maulwurfpfote, welche einem lebendigen Tier abgeschlagen wurde, sollte Glück bringen ${ }^{64}$. Das Abschlagen der rechten Maulwurfpfote und die anschließende Gewinnung von drei Tropfen Blut ist auch bei Jühling als Mittel gegen Amenorrhoe beschrieben ${ }^{65}$.

\subsection{Rezept gegen Hypermenorrhoe}

In dem Rezept Nr. 18 (S. 62) wird die Herstellung einer Arznei bei Hypermenorrhoe beschrieben. Brunnenkresse, die aus dem Brunnenzufluss entnommen wurde, soll mit Menstruationsblut gemischt und auf den Nabel gelegt werden, danach würde die Blutung vergehen.

Brunnenkresse wirkt harntreibend, von schwangeren Frauen soll sie nicht benutzt werden, da ihre Wirkung zu stark ist ${ }^{66}$. Brunnenkresse wurde als fruchttötende Droge und als Mittel zur Austreibung einer Todgeburt empfohlen. Auch Plinius beschrieb die Verwendung der Abortivdroge zur Fruchtaustreibung, wenn diese bereits tot war ${ }^{67}$. Nastutium officinale $\mathrm{R}$. Br. wird ebenfalls als Kraut in Salaten genutzt, der Samen wird wie Senf verwendet ${ }^{68}$.

\footnotetext{
${ }^{62}$ vgl. Mattioli, 1594- 1615, S. 106rB, vC, vD

${ }^{63}$ vgl. Dragendorff, 1967, S. 88

${ }^{64}$ vgl. HWdA, 1934/ 1935, Band VI, Sp. 12- 13

${ }^{65}$ vgl. Jühling, 1900, S. 121

${ }^{66}$ vgl. Mattioli, 1594- 1615, S. 246rA

${ }^{67}$ vgl. Leibrock- Plehn, 1992, S. 95 u. 125

${ }^{68}$ vgl. Dragendorff, 1967, S. 258
} 
Das Menstrualblut, welches durch die Hippokratiker als Ausscheidungsprodukt analog dem Stuhl und Harn beschrieben wurde, galt als giftig und unrein. Somit herrschte damals in der Gesellschaft die Annahme, dass das Bestreichen mit diesem Blut einen Abort auslösen könne. Weitere Anwendungsmöglichkeiten fanden sich bei inneren und äußeren Erkrankungen, wie beispielsweise bei Gicht, Furunkeln und Ausschlägen, als Antikonzeptivum wurde es ebenfalls verabreicht ${ }^{69}$. Betrachtet man die Arzneistoffe bezüglich ihrer Wirkungsweise, kann davon ausgegangen werden, dass sich der Kompilator vermutlich bezüglich der Indikationsstellung geirrt hatte. Alle verwendeten Bestandteile des Rezeptes wirkten einer Amenorrhoe entgegen.

\section{Der Uterus und dessen Pathologien}

\subsection{Uterusaufbau}

Die Beschreibung des Uterus als siebenkammeriges Organ ist die am häufigsten herangezogene Methode zur Erklärung von Zeugungsmerkmalen, wie das Geschlecht des Kindes, Mehrlingsschwangerschaften, oder Zwitterbildungen. Aufgeteilt wurden die Kammern in je drei auf jeder Seite und eine weitere, die siebte Kammer, in der Mitte. In den drei rechten Kammern wuchsen Jungen heran, in den drei linken die Mädchen und in der Mittleren kam es zu Zwitterbildung ${ }^{70}$.

\subsection{Uteruspathologien}

Von Aretaeus wurde der Uterus als ein Wesen im Wesen beschrieben. Eine Lageverschiebung, wie beispielsweise das Aufsteigen, verursachte Epilepsien oder gar Erstickungsanfälle. Da die ausgelösten Leiden als hysterisch bezeichnet wurden,

\footnotetext{
${ }^{69}$ vgl. Diepgen, 1937, S. 128

${ }^{70}$ vgl. Reisert, 1986, S. 7- 8
} 
entstand die Hysterietherapie in Form von angenehmen Reizungen von unten und unangenehmen Eindrücken von oben ${ }^{71}$. Die unangenehmen Gerüche durch die Nase sollten den Uterus von oben abschrecken, die wohlriechenden Medikamente von unten sollten die Gebärmutter nach unten locken ${ }^{72}$.

Der Uterus galt nicht nur als Sitz der Hysterie, sondern auch der pathogenen Bilder. Eine Molenschwangerschaft war beispielsweise als Folge einer "geilen Einbildung" entstanden, ein zu langes Betrachten im Spiegel führte zu einer Mutterähnlichkeit des Kindes. Die Imaginationslehre wurde als nützliches Instrument herangezogen, wenn Kinder dem Vater nicht ähnlich waren und es sich vermutlich um Kuckuckskinder handelte. Man verhinderte vaterlose Kinder, indem man die Frau beschuldigte, zu lange eine andere Person angeschaut zu haben ${ }^{73}$.

Die Ursache für ein Gebärmutterleiden war häufig eine Oligo- oder Amenorrhoe und nach humoralpathologischer Denkweise füllte nicht nur das verdorbene böse Menstrualblut die Gebärmutter und entartete dort, sondern machte sich auch im Kopf und in den Augen der Patientin bemerkbar ${ }^{74}$. Zur Vermeidung einer Erkrankung der Gebärmutter war regelmäßiger Geschlechtsverkehr empfohlen. Der Uterus einer Abstinenten war trocken und verursachte Schmerzen bei der Menstruation ${ }^{75}$.

\subsection{Rezepte bei Gebärmutterleiden}

Das Rezept Nr. 7 (S. 57) beschreibt eine Arznei, um eine Frauenkrankheit „weibes siechtum", hier das Anschwellen um den Nabel, zu behandeln. Vermutlich wird damit die Gebärmutter gemeint. Als Folge fault der Frau, wie auch Eier faulen, das in der Leber vorhandene Blut, die Fäulnis steigt wie Rauch in ihr Gehirn auf. Ursächlich könnte eine Lageverschiebung des Uterus oder eine Amenorrhoe solche Symptome verursacht haben. Zur Besserung der Beschwerden empfiehlt der Kompilator Nesselsamen in Wein oder in sämigem Honig zu sieden und dieses der Frau zu

\footnotetext{
${ }^{71}$ vgl. Fischer- Homberger, 1988, S. 125

72 vgl. Diepgen, 1937, S. 260

${ }^{73}$ vgl. Fischer- Homberger, 1988, S. 21- 22

${ }^{74}$ vgl. Kotsch/ Keil, 2008/09, S. 58

${ }^{75}$ vgl. Diepgen 1937, S. 143
} 
geben. In gleicher Weise soll Raute mit Honig gemischt werden und innerlich im Körper der Frau wirken. Ebenfalls wird die Arznei um die Scham herum aufgetragen. Wenn die Frau jedoch schnell gesund werden möchte, werden Linsen in Wein gebeizt und anschließend mit Honig vermischt. Diese Arznei soll jeden Tag benutzt werden.

Die Wirkungsweise der in Europa zu findenden Nesseln wurde bereits in Rezept Nr. 17 beschrieben.

Der Wein zählte neben Wasser, Milch und Bier als die am häufigsten verwendete Grundlage für Heiltränke ${ }^{76}$. Für Hildegard von Bingen ist der Wein das Blut der Erde und der Motor im Säftekreislauf des Menschen. Augustinus erkennt im Wein ebenfalls heilende Eigenschaften, er soll kräftigend wirken, Wunden heilen und Seelen trösten ${ }^{77}$. Es sind circa 250 Arten des Weines bekannt, Vitis vinifera L. gilt als die Stammpflanze. Neben dem gegorenen Saft werden die Trauben und unreifen Beeren als Arznei verwendet, ebenso auch die Weinranken und die Blätter, diese wurden bereits im Rezept Nr. 15 beschrieben ${ }^{78}$.

Honig wurde als Süßungsmittel in Arzneigetränken, vermutlich um die bitterschmeckenden Pflanzen einnahmefreundlicher zu gestalten, verwendet. Ebenfalls war er Grundbestandteil bei der Herstellung von Tabletten und Pillen, um diese $z u$ formen ${ }^{79}$. Äußerlich angewendet half er gegen Dermatosen und schlecht heilende Wunden ${ }^{80}$.

Die Verwendung der Raute wurde im Rezept Nr. 4 bereits aufgeführt. Bei Dioskurides findet speziell die Weinraute Anwendung bei Aufblähungen und Krämpfen der Gebärmutter. In der salernitanischen Pharmakologie wurde die Raute innerlich und äußerlich in Form von Tränken, Pessaren und Bähungen verabreicht, sie fand als Emmenagogum, Uterotonikum und Abortivum Anwendung ${ }^{81}$.

Linsen waren in ihrer Eigenschaft mittelmäßig warm und kalt und trocken im anderen Grad. Anwendung fanden sie bei Hypermenorrhoe und unkeuschen Gelüsten.

\footnotetext{
${ }^{76}$ vgl. Kruse, 1996, S. 81

${ }^{77}$ vgl. von Bingen, 1985, S. 121

${ }^{78} \mathrm{vgl}$. Dragendorff, 1967, S. 415

${ }^{79}$ vgl. Kruse, 1996, S. 83- 85

${ }^{80}$ vgl. Kotsch/ Keil, 2008/ 09, S. 64

${ }^{81}$ vgl. Kotsch/ Keil, 2008/09 S. 59 und S. 83
} 
Äußerlich angewendet wirkten sie blutstillend bei Wunden sowie einer Mastitis entgegen ${ }^{82}$.

Das Rezept Nr. 12 (S. 60) beschreibt die Behandlung eines Geschwürs in der Gebärmutter. Dieses soll sich nach dem Kompilator der Schrift häufig ereignen, so dass die Frau davon krank wird. Die Frau fühlt sich, als würde ihr ganzer Körper erfrieren, und sie fühlt das Geschwür, wenn sie sich an den Bauch greift. Zur Behandlung wird Bärenfett empfohlen, dieses soll in weicher Wolle eingearbeitet und anschließend an die Gebärmutter gelegt werden.

Die Wolle diente als Arzneistoffträger und wurde wahrscheinlich als Tampon oder Pessar eingeführt.

Bärenschmalz wurde vielfältig bei der Herstellung von Medikamenten verwendet. Es wurde beispielsweise zur Therapie des Haarausfalls benutzt ${ }^{83}$. Das Schmalz, welches von den Nieren des Bären gewonnen wurde, half gegen Erysipele, Phlegmonen, Karbunkel und Herpes. Zur Therapie der Geschwüre wurde es ebenfalls verwendet ${ }^{84}$.

Im Rezept Nr. 26 (S. 66) findet sich eine Arznei bei faulender Gebärmutter. Wahrscheinlich handelt es sich um ein Krebsgeschwür. Hierzu empfiehlt der Kompilator Eier und gut gebrannten Lehm oder Lehm aus einem Ofen zu verwenden, diese zu zermahlen und anschließend mit Essig zu vermischen. Dies soll so lange gesiedet werden, bis das Wasser verkocht ist, anschließend wird es durch ein Tuch gewrungen und mit dem dritten Teil so viel Öl und Honig gemischt. Aus der Masse sollen Stückchen oder Kügelchen geformt werden und, vaginal eingeführt, für zwei oder drei Stunden belassen werden. Diese Arznei soll auch bei anderen faulenden Wunden helfen. Als weitere Applikationsform wird die Räucherung beschrieben. Hier

\footnotetext{
${ }^{82}$ vgl. Mattioli, 1594- 1615, S.122vD, S. 123rA, rB, vC

${ }^{83} \mathrm{vgl}$. Lonicerus, 1679 , S. 614

${ }^{84} \mathrm{vgl}$. Jühling, 1900, S. 1-2
} 
sollen die Kügelchen oder Stückchen mit starkem Wein auf einen heißen Stein gegossen werden und der entstehende Dampf in die Scham geleitet werden.

Der hartgekochte Eidotter war allgemein als Analgetikum bekannt, besonders das Eieröl half bei Ohren-und Gelenkschmerzen sowie innerlich bei Abdominalbeschwerden ${ }^{85}$. Das Ei war mittelmäßiger Natur, es war nicht zu kalt und nicht zu warm. Eigelb heilte Geschwüre. Gänseeier wurden als Emmenagogum innerlich in der Gebärmutter angewendet ${ }^{86}$.

Der Lehm wurde wahrscheinlich als Bindematerial verwendet, aber auch die Fähigkeit zur Wärmespeicherung dieser Substanz könnte die Wirkung des Medikamentes verstärkt haben.

Weinessig wurde als Mittel gegen Aszites und bei Blutungen äußerlich und innerlich angewendet ${ }^{87}$. Der Essig besitzt kühlende, entzündungshemmende und adstringierende Eigenschaften. Er sollte den Gebärmuttervorfall und Geschwüre heilen. Krebsgeschwüre wurden durch Bähung mit Essig im Wachstum aufgehalten ${ }^{88}$.

Das Öl wurde ursprünglich aus den Früchten des Ölbaums hergestellt. In der Volksmedizin wurden Öle zu verschiedenen Heilzwecken eingesetzt. Von der Anwendung versprach man sich zusammenziehende Eigenschaften. Das Öl wurde als Klistier verwendet, um Geschwüre in After, Uterus und Vagina zu heilen ${ }^{89}$. Das ÖI könnte im obigen Rezept mit dem Honig als Wirkstoffträger fungiert haben. Geht man jedoch von dem in anderen Rezepten empfohlenen Rosenöl aus, gibt es zu diesem eine pharmazeutische Wirkung. Rosenöl wirkt kühlend und hilft bei Verbrennungen oder Geschwüren ${ }^{90}$. Es fand auch als Analgetikum Anwendung ${ }^{91}$.

Die Verwendung des Honigs findet sich im Rezept Nr. 7 und auf die Applikationsform der Räucherung wurde im Rezept Nr. 5 eingegangen.

\footnotetext{
${ }^{85}$ vgl. Kotsch/ Keil, 2008/ 09, S. 56

${ }^{86} \mathrm{vgl}$. Lonicerus, 1679 , S. 635- 636

${ }^{87}$ vgl. Mattioli, 1594- 1615, S. 447rB

${ }^{88}$ vgl. Dioskurides, 1902, S. 488- 489

${ }^{89}$ vgl. HWdA, 1934/ 1935, Band VI, Sp. 1238- 1239

${ }^{90}$ vgl. Mattioli, 1594- 1615, S. 56vC

${ }^{91}$ vgl. Kotsch/ Keil, 2008/ 09, S. 56
} 
Das Rezept Nr. 9 (S. 58) behandelt eine Krankheit, die nach mittelalterlicher Auffassung entstand, wenn Frauen zu lange ohne Geschlechtsverkehr lebten. Die Folge war ein Anschwellen der Gebärmutter, der Grund für die Erkrankung war die Zurückhaltung des weiblichen Samens ${ }^{92}$. Der weibliche Samen galt bei Galen als besonders kühl und feucht, wenn er zu lange zurückgehalten würde, könne großes Unheil entstehen ${ }^{93}$. Der Kompilator der römischen Handschrift beschreibt diese Erkrankung folgendermaßen: Einige Frauen wären verwundet und krank in der Gebärmutter, weil sie nicht mehr benutzt würden. Betroffen waren Witwen, Jungfrauen und Frauen, deren Männer längere Zeit fort seien. Diese Frauen sollten Salbei in Essig beizen und diesen anschließend im Mund behalten. Als Weiteres sollten sie Schwefel in Essig beizen und sich die Schienbeine damit einreiben. Durch diese Prozedur erfahren die Frauen Besserung.

Die Wirkung des Essigs wurde bereits im Rezept Nr. 26 beschrieben und auch die Wirkung des Salbeis findet sich im Rezept Nr. 4.

Der Schwefel galt als heiß und trocken. Es existieren zwei Schwefelarten, der tote Schwefel, Sulfur sublimatum, welcher bereits erhitzt wurde und der lebendige Schwefel, Sulfur vivum, der nicht erhitzt wurde. Sulfur sublimatum wurde bei Krätze, Flechten, Geschwüren und Nervenerkrankungen eingesetz ${ }^{94}$. Dioskurides sieht den nicht erhitzten Schwefel als den Besseren an, wurde dieser als Räucherung appliziert, wirkte er austreibend auf den Embryo ${ }^{95}$.

Die erstgenannte Applikationsform, das Medikament im Mund zu halten, stellt einen Teil der inneren Anwendung dar, der Wirkstoff sollte vermutlich über die Zunge aufgenommen werden. Weitere innere Anwendungsformen waren die der Inhalation eines Geruchs über die Nase und die Arzneigabe über Tränke ${ }^{96}$. Die Einreibung der Schienbeine könnte an Stelle des Aderlasses eingesetzt worden sein. Die Frau als Laie konnte dies ohne medizinische Fachhilfe eigenständig durchführen. Nach Galen wurde eine Phlebotomie zur Behandlung eines Säfteüberschusses oder bei veränderten Säftemassen durchgeführt. Hierbei fanden zwei Methoden ihre Anwendung, die der Derivation und die der Revulsion. Bei der Derivation wurde eine

\footnotetext{
${ }^{92}$ vgl. Kruse, 1996, S. 93

${ }^{93}$ vgl. Diepgen, 1937, S. 144

${ }^{94}$ vgl. Mildenberger, 1997, S. 1926

${ }^{95}$ vgl. Dioskurides, 1902, S. 534

${ }^{96}$ vgl. Kruse, 1996, S. 84- 86
} 
Vene in der Nähe des erkrankten Organs eröffnet, bei der Revulsion schnitt man entfernt vom erkrankten Organ, um die Säfte auf ein anderes Körperteil zu lenken. Im Falle einer Menstruationsstörung wurde das Verfahren der Derivation an den uns heute bekannten Venae saphenae magna et. parva durchgeführt ${ }^{97}$. Der Verlauf der beiden Venen stellt nach heutigem Wissensstand keine direkte Verbindung zum Schienbein dar, die V. saphena magna verläuft medial des Unterschenkels, während die V. saphena parva von dorsal nach lateral verläuft. Jedoch kann der heutige Wissensstand nicht mit dem im Mittelalter verglichen werden. Daher ist die Anwendung am Schienbein, welches in der Nähe der Venen zu finden ist, vermutlich ein gerechtfertigter Ort, um das Medikament aufzutragen.

Das Rezept Nr. 10 (S. 59) beschreibt ebenfalls den Zustand des fehlenden Geschlechtslebens der Frau. Infolgedessen schwillt innen der Uterus und sie werden cholerisch. Die Adern und die Augen vertrocknen. Eine Randnotiz in der Handschrift fügt hinzu, dass auch das äußere Genital, hier als "fot“ bezeichnet, anschwillt. Die Frau ist innerlich und äußerlich erkrankt, auch die Ohren laufen. Zur Heilung empfiehlt der Kompilator Rosenöl und die Milch einer knabenstillenden Frau über Kohlen zu erwärmen. Anschließend soll weiche Wolle darin gewälzt und an den Uterus gestoßen werden. Wenn dies nicht hilft, soll Galgan und Rosenöl vermischt und in gleicher Weise angewendet werden.

„Ein bei allen Völkern berühmtes Heilmittel und ein berühmter Fruchtbarkeitsüberträger ist die Frauenmilch“98. Die Milch einer Frau, die einen Jungen stillt, wurde im Heilzauber vorgezogen. Allgemein wirkt die Frauenmilch heilend, kräftigend und kühlend, sie gibt einem Mann seine Manneskraft zurück und wurde bei Podagra und Magenbeschwerden eingesetzt ${ }^{99}$.

Über die Anwendung des Rosenöls wurde bereits im Rezept Nr. 12 geschrieben.

Der Galgan war heiß und trocken im dritten Grad. Innerlich angewendet half er bei verschiedenen Krankheiten. Er stärkt den Magen und wirkt verdauungsfördernd ${ }^{100}$. Es existieren zweierlei Arten des Galgans, der große und der kleine Galgan. Sie unterscheiden sich im Aussehen der Wurzel, ihrem Geruch und Geschmack. Er

\footnotetext{
${ }^{97}$ vgl. Diepgen, 1937, S. 249- 250

${ }^{98}$ HWdA, 1934/1935, Band VI, Sp. 276

${ }^{99}$ vgl. HWdA, 1934/1935, Band VI, Sp 277- 279

100 vgl. Mattioli, 1594- 1615, S. 5vD
} 
wurde vielfach eingesetzt bei Krankheiten, die kalter Natur waren. Er wirkt appetitanregend, gedächtnisfördernd, gegen Ohnmachtsanfälle und Herzrhythmusstörungen ${ }^{101}$.

Im Rezept Nr. 13 (S. 60) wird eine Arznei zur Linderung von Gebärmutterschmerzen beschrieben. Durch die starken Schmerzen fühlt sich die Frau eingeengt oder gefesselt. Zur Linderung sollen Hirschmark und ein gebratener Eidotter mit Rosenöl gemischt werden, so dass eine sämige Masse wie Honig entsteht. Diese Mischung wird als Pflaster an die Scham gelegt. Wenn man diese Zutaten nicht besitzt, soll man Myrre mit gekochtem Wein trinken.

Das Hirschmark der langen Röhrenknochen stellte die Grundlage des Pflasters dar ${ }^{102}$. Hirschmark wurde bei Schmerzen und Frakturen benutzt, es wirkte emmenagog und gegen Geschwüre der Gebärmutter ${ }^{103}$.

Über die Verwendung des Eies wurde im Rezept Nr. 12 geschrieben. Das Braten des Eies könnte an dieser Stelle für eine heißere Thermik gesorgt haben.

Die Anwendungsbereiche des Rosenöls wurden im Rezept Nr. 12 beschrieben.

Die Myrre war warmer und trockener Natur, äußerlich an die Scham gelegt wirkte sie als Emmenagogum und Abortivum ${ }^{104}$. Sie besitzt erwärmende, betäubende, verklebende und adstringierende Eigenschaften. In Verbindung mit Wermut und einer Lupinenabkochung als Zäpfchen eingeführt, erweicht und öffnet sie die Gebärmutter und entfaltete die oben beschriebene Wirkung. Die Myrre ist das Gummiharz von Balsamea Myrrha, eines dornigen Baumes oder Strauches. Sie enthält 40-67\% Gummi, 2- 6,5\% ätherisches Öl und 28-35\% Harz ${ }^{105}$.

\footnotetext{
${ }^{101}$ vgl. Lonicerus, 1679, S. 538

102 vgl. Kotsch/ Keil, 1997, S. 56

${ }^{103}$ vgl. Jühling, 1900, S. 60- 61

${ }^{104}$ vgl. Mattioli, 1594- 1615, S. 20vC

105 vgl. Dioskurides, 1902, S. 79- 80
} 
Das Rezept Nr. 14 (S. 60) enthält ebenfalls eine Arznei bei Gebärmutterschmerzen, infolge eines Blutstaus in der Gebärmutter. Der Kompilator beschreibt, dass den Frauen die Augenbrauen blätterrot und weniger werden, die Augen werden blutfarbig und das hohe Fieber überwältigt sie. Hierzu sollen Sadebaum ${ }^{106}$ und Rauten mit Wein gemischt und anschließend getrunken werden, bis dass es der Frau besser geht. Alternativ sollten die Nieren eines Stiers in Wasser gesiedet und anschließend mit kochendem Öl vermischt werden. Diese Arznei wurde anschließend auf ein Tuch gestrichen und Safran hinzugefügt. Das Ganze wurde auf den Ort, in dem das Übel saß, gelegt, daraufhin sollte die Heilung erfolgen.

Das Blut eines Opferstiers konnte heilende aber auch tödliche Wirkung haben. A $B$ eine schwangere Frau Stierfleisch, wurde das Kind geil. Stiergalle wurde bei Dioskurides und Plinius als eine wirksame Gallenart beschrieben. Stiergalle, mit Honig gekocht, half gegen Gebärmutterschmerzen und Geschwüre. Das Stiermark wurde auf Kontrakturen gelegt ${ }^{107}$. Die Verwendung der Stierniere ist in keiner der spezifischen Rezeptsammlungen zu finden, möglicherweise sah der Kompilator in der Niere als Ausscheidungs- und Reinigungsorgan die Möglichkeit, die Reinigung des Körpers durch die Gabe einer weiteren Niere unterstützen zu können. Vielleicht versprach sich der Kompilator, durch eine Verstärkung der Diurese, als Analogie der Menstruation zu dem Urin, das verstockte Blut aus der Gebärmutter auszuscheiden.

Der Safran besitzt diuretische Eigenschaften und fand als Emmenagogum Anwendung. Er wurde bei entzündeten Geschwüren eingesetzt ${ }^{108}$. Crocus sativus L. enthält Crocin und ätherisches Öl, die Narben wurden bereits im Altertum als Stimulans und Antispasmotikum genutzt ${ }^{109}$.

Die Verwendung der Raute und des Sadebaums wurde im Rezept Nr. 4 und die des Weins im Rezept Nr. 7 aufgeführt. Die Anwendung des Öls findet sich im Rezept Nr. 12. Das in diesem Rezept verwendete Öl diente vermutlich als Trägerstoff des Medikamentes.

\footnotetext{
${ }^{106}$ der Sadebaum wurde unter verschiedenen Namen geführt, auch als Zepperbom, vgl. Brøndegaard, 1994, S. 344, welches dem „Czippernbawn“ des Kompilators ähnlich ist. Die Verwendung des Sadebaums in diesem Rezept erscheint plausibel.

${ }^{107}$ vgl. HWdA, 1936/ 1937, Band VIII, Sp. 484- 485

108 vgl. Mattioli, 1594- 1615, S. 18vD- 19rA

109 vgl. Dragendorff, 1967, S. 139
} 
Die im Rezept beschriebene Symptomatik lässt den humoralpathologischen Ansatz erkennen. Das giftige aufgestockte Blut fährt der Frau in den Kopf und verursacht dort Symptome. Unterstrichen wird dies durch die bildliche Beschreibung, dass sich der gesamte Bereich der Augen „rot“ verfärbt.

Das Rezept Nr. 34 (S. 69) beinhaltet die Herstellung einer Arznei, um das Aufsteigen der Gebärmutter zu heilen. Zur Heilung wird Wermut in Wasser gekocht, dieses Dekokt soll anschließend getrunken werden.

Auf die Verwendung des Wermuts wurde im Rezept Nr. 4 eingegangen.

In dem Rezept Nr. 35 (S. 70) findet sich hingegen eine Arznei gegen das Absinken der Gebärmutter. Es handelte sich hier womöglich um einen Descensus uteri. Hierzu sollen Nesseln in Wasser gesiedet und anschließend über die Scham "heimliche stat", gelegt werden.

Die Indikation und Wirkungsweise zur Nessel wurde im Rezept Nr. 17 beschrieben.

Das Rezept Nr. 40 (S. 71) beinhaltet eine Sammlung verschiedener Mittel, die einer Gebärmutterbewegung entgegen wirken sollten. Zum einen wird die Möglichkeit beschrieben, das Horn eines Bockes zu entzünden und den Rauch, bei verschlossenem Mund und Augen, in die Nase gehen zu lassen. Ein weiteres probates Mittel, welches an Wirkung nicht zu übertreffen ist, stellt Kuhmist dar, der im Mai aufgekocht und getrunken werden soll, wenn die Gebärmutter wandert. Was in seiner Wirkung ebenfalls als das Beste beschrieben ist, stellt das „abgeschlagene Arschlochwasser" dar. Oder man sollte Saxifraga benutzen, da dies ebenfalls gut hilft. 
Tierhörner oder Geweihe und auch der Kuhmist stellten wesentliche Bestandteile der Dreckapotheke dar. Die Dreckapotheke beinhaltet die Nutzung menschlicher und tierischer Ausscheidungsprodukte sowie anderer Bestandteile. Im Jahre 1652 führte die Dresdner Apotheke fünfzig tierische Fette auf. „Urin war Universalmed., menschl. Kot galt als bes. heilsam, Speichel und Frauenmilch wurden viel verwendet“" ${ }^{110}$. Hirschhorn, Hasenhaar und Schweinekot wurden zur Blutstillung verwendet. Der Erfolg der Dreckapotheke hing von dem Glauben des Patienten an dessen Wirkung ab. Auch heute finden wir Substanzen, die der Dreckapotheke angehören, wie beispielsweise das Fischöl, welches wichtige Omegafettsäuren liefert und die Blutfettwerte günstig beeinflusst ${ }^{111}$. Die Verwendung des Kuhmistes, welcher im Mai zubereitet wurde, geht auf die Annahme zurück, dass gerade der Mai das körperliche Gedeihen des Menschen fördert und dieser die Zeit des Lenzes, der Liebe und der Hoffnung war. Bestandteile von Arzneien sollten im Mai gesammelt werden, als Beispiel seien schwarze Schnecken genannt, die, zu Öl verarbeitet, zur Heilung von Wunden dienten ${ }^{112}$.

Das „abgeschlagene Arschlochwasser" war vermutlich ebenfalls ein Bestandteil der Dreckapotheke, wahrscheinlich setzte der Kompilator dies mit dem menschlichen Kot gleich.

Saxifraga wurde als Emmenagogum verwendet ${ }^{113}$. Es sind über 600 Arten der Saxifragaceae bekannt. In den Wurzeln und Rinden einiger Sorten finden sich Gallussäure, Gerbstoff, Glycoside und aromatische Bestandteile. Die in Europa zu findenden Sorten sind Saxifraga granulata L. und Saxifraga bulbifera L., deren Kraut, Knollen und Samen gegen Stein- und Brustleiden eingesetzt wurden. Weiter existiert Saxifraga tridactylites L., welches gegen Ikterus und Drüsenverhärtungen seine Anwendung fand. Die Wurzel von Saxifraga cordifolia L. und Saxifraga Cotyledon L. waren wirksam gegen Fäulnis und die Wurzel von Saxifraga ligulata Bell. war wirksam bei Furunkeln und Augenentzündungen ${ }^{114}$.

\footnotetext{
${ }^{110}$ Tshisuaka, 2005, S. 323

${ }^{111}$ vgl. Tshisuaka, 2005, S. 322- 323

${ }^{112}$ vgl. HWdA, 1932/ 1933, Band V, Sp. 1512- 1513

${ }^{113}$ vgl. Mattioli, 1594- 1615, S. 335rA

${ }^{114}$ vgl. Dragendorff, 1967, S. 267
} 
Das Rezept Nr. 48 (S. 74) enthält eine Arznei gegen Gebärmutterschmerzen. Hierzu werden zwei Unzen Galgan und zwei Unzen Lorbeer zerrieben und miteinander vermischt. Ein kleiner Löffel von dem Pulver soll in Weißwein getrunken werden, dies führt zur Heilung.

Die Verwendung des Galgans wurde im Rezept Nr. 10 und die des Weins im Rezept Nr. 7 beschrieben.

Lorbeerblätter und Lorbeeren waren warm und trocken im dritten Grad. Äußerlich angewendet halfen sie gegen die verschiedenen Krankheiten der Gebärmutter und der Blase, sie wirken diuretisch und förderten die Menstruationsblutung. Wurden die Blätter mit Brot aufgelegt, halfen sie, eine entzündete Geschwulst zu heilen ${ }^{115}$. Laurus nobilis L., dessen Blätter und Früchte eine ziehende Wirkung besitzen, enthalten Laurostearin, Myristin und ätherisches Öl. Der Lorbeer wird von Dioskurides und Galen erstmals als Arzneipflanze erwähnt ${ }^{116}$.

\section{Die Behandlungsmethoden des äußeren Genitals}

\subsection{Anatomisches Verständnis in der Antike}

Mit der Anatomie des äußeren Genitals der Frau beschäftigte sich die Medizin eher weniger. Die Hippokratiker benennen einzelne Bereiche des äußeren Genitals, ohne jedoch näher auf deren Funktion einzugehen, ob innen das Hymen bekannt war, ist nicht zu sagen. Die Scheide wurde als Teil des Uterus angenommen, somit ist es schwierig die heutige Terminologie mit der der Hippokratiker zu vergleichen. Galen beschreibt die Labien als eine Art Wärmeschutz und Schmuck, ohne jedoch zwischen den kleinen und großen Schamlippen zu unterscheiden. Soran beschrieb an der Stelle, wo die Labien zusammentreffen, den Beginn der Harnröhre, dies entspricht der heutigen Klitoris ${ }^{117}$.

\footnotetext{
${ }^{115}$ vgl. Mattioli, 1594- 1615, S. 34vC, vD

${ }^{116}$ vgl. Dragendorff, 1967, S. 245

${ }^{117}$ vgl. Diepgen, 1937, S. 130- 131
} 


\subsection{Die Krankheiten des äußeren Genitals und deren Therapie}

Das Rezept Nr. 8 (S. 58) beschreibt vermutlich eine Behandlungsmethode der Vaginitis. Der Kompilator beschreibt unter der Überschrift „von weib siechtum“, dass es Frauen gäbe, bei denen sich „der Ort" entzündet, nachdem man mit innen Verkehr hatte. Zur Behandlung empfiehlt er, Thymian und Lavendel ${ }^{118}$ mit Gänsefett zu vermischen und dies an der Scheide aufzubringen.

Der Thymian war in seiner Natur warm und trocken im dritten Grad. Innerlich angewendet wirkt er diuretisch und wurde als Emmenagogum eingesetzt. Er besitzt austreibende Eigenschaften auf die Leibesfrucht und auf die Plazenta. Äußerlich verwendet heilt er Geschwüre ${ }^{119}$. Thymus vulgaris L. besitzt ein ätherisches Öl welches Thymol, Carvacrol, Cymol und Bornylester enthält. Das Kraut wurde als Stomachikum, Carminativum und Antiseptikum verwendet ${ }^{120}$.

Der Spicanardi, auch deutscher Spick genannt, ist heute unter dem Namen Lavendel bekannt. Die Blüten des Spick wirken diuretisch, emmenagog und wurden zur Förderung der Plazenta post partum eingesetzt. Lavendelwasser wurde bei Zahnschmerzen und Geschwüren im Mundbereich verwendet ${ }^{121}$. Lavandula vera D. C. enthält ätherisches Öl mit Linalool, Linalylacetat, Geraniol, Cineol. Die Blüten wurden innerlich bei Koliken und Flatulenzen und äußerlich als Umschläge oder zur Einreibung benutzt. Lavandula spica D. C., auch deutsche Narde genannt, diente als Ersatz der obigen ${ }^{122}$.

Das Gänsefett wurde vermutlich als Salbengrundlage benutzt.

\footnotetext{
${ }^{118}$ bei „sackten“ könnte es sich um eine verderbte Form von saccus handeln, welches Sack oder Tasche bedeutet, vgl. Lexer, 1992, S. 174, im Text könnten damit die Blütentaschen gemeint sein. Bei dem Wort „spicerei“ handelt es sich wahrscheinlich um eine verderbte Form von Spicanardi.

${ }^{119}$ vgl. Mattioli, 1594- 1615, S. 248vD

${ }^{120}$ vgl. Dragendorff, 1967, S. 582

${ }^{121}$ vgl. Lonicerus, 1679, S. 285- 286

122 vgl. Dragendorff, 1967, S. 571
} 
Das Rezept Nr. 47 (S. 74) beschreibt die Behandlung von Schmerzen der Vagina. Die vermutliche Ursache hierfür könnte die heute bekannte Bartholinitis sein. Der Kompilator beschreibt dies durch eine schmerzhafte Erhebung am Rand. Die Frauen sollen, um wieder gesund zu werden, Hüttenrauch ${ }^{123}$ und eine Handvoll Salbei miteinander in Weißwein sieden und anschließend mit dem Wein die Stelle benetzen.

Der Hüttenrauch ist in seiner Art dem Schwefel gleich. In seiner Natur war er heiß und trocken im vierten Grad, er wirkt zusammenziehend und besitzt eine ätzende Wirkung ${ }^{124}$. Er wirkt kühlend, reinigend, verklebend und austrocknend ${ }^{125}$.

Die Verwendung des Salbeis wurde bereits im Rezept Nr. 4 beschrieben. Die Anwendungsbereiche des Weins finden sich im Rezept Nr. 7.

\section{Die Brustdrüse und deren Pathologien}

Die Darstellung der weiblichen Brust beschränkt sich in den medizinischen Schriften lediglich auf ihre Funktion als Stillorgan. Avicenna war der Einzige, der der Brust auch beim Liebesspiel einen wichtigen Platz einräumte, andere Autoren hielten sich diesbezüglich zurück. Kleine feste Brüste wurden beschrieben, jedoch nicht in erotischer Absicht, in Portraits alter Frauen wurden die Brüste hängend, als Zeichen des Verfalls dargestellt ${ }^{126}$. Die bekannten Erkrankungen der Brust erstreckten sich über diejenigen, welche das Wochenbett mit sich brachte, über lokale Affektionen der Brustdrüse bis zu den krankhaften Veränderungen, welche durch eine andere Erkrankung verursacht wurden. Beispielsweise führte eine Erkrankung des Uterus zu einer Gelbfärbung der Brustwarzen. Frauen, die ihre Brüste verloren hatten, bekamen nach hippokratischer Meinung eine kräftige Stimme, fühlten sich allgemein unwohl und litten unter Kopfschmerzen. Auch eine Schwangerschaft sollten sie

\footnotetext{
${ }^{123}$ bei „perporo“ handelt es sich vermutlich um eine verderbte Formulierung, die auf das lateinische Wort porro zurück geht und steigernde Bedeutung ausdrücken soll, vgl. Menge, 1988, S. 580, weiter wird angenommen das der Kompilator anstelle des „tucio“, tuttian den Hüttenrauch meinte, vgl. Rohland, 1982, S. 549

${ }^{124}$ vgl. Lonicerus, 1679 , S. 716

${ }^{125}$ vgl. Dioskurides, 1902, S. 507

${ }^{126}$ vgl. Thomasset, 1993, S. 60
} 
vermeiden, da die Milch aus dem Uterus nicht mehr zu den Brüsten gelangen konnte und somit in die Lunge und in das Herz fließt, dies sollte dazu führen, dass die Frauen daran erstickten ${ }^{127}$.

\subsection{Möglichkeiten der Brustverkleinerung}

Im Rezept Nr. 43 (S. 72) empfiehlt der Kompilator, um ein fortschreitendes Wachstum der Brust zu vermeiden, Mohnsamen in Regenwasser zu sieden, anschließend in ein Tuch zu geben und dieses drei Tage über die Brüste zu legen. Eine weitere Möglichkeit stellten grüne Rosspappeln ${ }^{128}$ dar, welche zerstoßen als Pflaster auf die Brust gelegt werden sollten. Weiter empfiehlt der Kompilator Vogelkraut ${ }^{129}$, welches ebenfalls aufgelegt werden sollte.

Der Mohn, Papaver somniferum L., enthält in seinem Milchsaft, welches als Opium verwendet wird, unter anderem 8-10\% Morphin, 0,2- 0,8\% Codein und 0,2- 0,3\% Thebain. Der Samen wird zu Öl verarbeitet oder zur Herstellung von Emulsionen benutzt. Die unreife Frucht wird als Hypnotikum und Tranquilizer verwendet ${ }^{130}$. Neben dem weißen und schwarzen Mohn sind weitere Varianten des Mohns bekannt. Papaver wurde auch Magenkraut genannt. Der weiße wie auch der schwarze Mohn wirken reinigend und beruhigend, jedoch besitzt der weiße die stärkere Wirkung ${ }^{131}$. „Als gefährliches Gift wurde auch der Schlafmohn eingeschätzt, von dem Isaak Judäus sagt, er sei in der Lage, das Leben auszulöschen" ${ }^{132}$. Lonicerus nennt den Mohn, „Magsaamen“. Der Weiße war kalter und feuchter Natur, während der Schwarze kalter und trockener Natur war. Das Kraut des weißen Mohns

\footnotetext{
${ }^{127}$ vgl. Diepgen, 1937, S. 236

${ }^{128}$ der Kompilator nennt sie „Melden“, im Vergleich mit anderen Codices findet sich bei Makromastie die Gabe von wilden malcen, vgl. Kotsch/ Keil, 2008/ 09, S. 65, die der Rosspappel entsprechen.

${ }^{129}$ Der Kompilator nennt es „Veltkraut“, im Vergleich mit anderen Codices findet sich bei der Behandlung der Brusterkrankungen Vogelkraut, welches dem Gemeinen Greiskraut, bzw. dem Gemeinen Kreuzkraut entspricht. vgl. Kotsch/ Keil, 2008/ 09, S. 66

${ }^{130}$ vgl. Dragendorff, 1967, S. 249

${ }^{131}$ vgl. Mildenberger, 1997, S. 1399- 1400

${ }^{132}$ Kotsch/ Keil, 2008/ 09, S. 66
} 
wurde zur Behandlung von Geschwüren verwendet. Der Samen wirkt gegen Fieber und Entzündungen ${ }^{133}$.

Das Regenwasser galt als besonders rein $^{134}$.

Die Rosspappel, Malva silvestris L., gehört zur Gruppe der Malvaceae. Aus dieser Gattung sind circa 650 Arten bekannt, welche als Kräuter, Sträucher und Bäume Schleimschläuche in der Rinde und im Mark enthalten. Bei manchen Arten enthalten die Blätter Oxalate, andere enthalten moschusartige Geruchsstoffe. Blätter und Blüten werden als schleimhaltiges Medikament, als Gurgelwässer oder bei der Herstellung von Umschlägen verwendet ${ }^{135}$. Die Pappel wirkt reizmildernd bei entzündeten Geschwüren, der Malvenumschlag erweicht Drüsen und Geschwüre ${ }^{136}$.

Das Vogelkraut besitzt eine antiseptische Wirkung. Es wurde zur Behandlung einer Entzündung eingesetzt. Das Kraut, zusammen mit Wein gekocht, heilte die Erkrankungen der Brüste. Der Saft des Vogelkrauts wurde bei faulen Wunden eingesetzt ${ }^{137}$. Das Vogelkraut ist das heute bekannte Kreuzkraut, auch Senecio vulgaris L. genannt. Der Saft wurde gegen Menstruationsbeschwerden, hysterische Krämpfe und Epilepsie verwendet. Äußerlich fand das Kraut gegen Hämorrhoiden, Verhärtungen der Brust und Carbunkel seine Anwendung. Es enthält unter anderem die zwei Alkaloide Senecionin und Senecin ${ }^{138}$. Senecionin ist ein hepatotoxisches Zellgift ${ }^{139}$.

Die heutige Vorstellung, dass ein eher größerer Busen dem Idealbild entspricht, kann in die Schönheitsvorstellung des Mittelalters nicht übertragen werden. Hier wurde eher auf kleine Brüste Wert gelegt. Die Rezepte gegen Makromastie erfüllten jedoch einen weiteren Zweck, nämlich den zur Verhinderung eines Brustkrebses. Der Autor

\footnotetext{
${ }^{133}$ vgl. Lonicerus, 1679, S. 208- 209

${ }^{134}$ vgl. Kotsch/ Keil, 2008/09, S. 66

${ }^{135}$ vgl. Dragendorff, 1967, S. 421

${ }^{136}$ vgl. Mildenberger, 1997, S. 1402

${ }^{137}$ vgl. Lonicerus, 1679, S. 376

${ }^{138}$ vgl. Dragendorff, 1967, S. 681

139 vgl. Kotsch/ Keil, 2008/ 09, S. 66
} 
des „Erlauer Frauenbüchlein“ beschreibt die Gefahr der Krebsentstehung in größeren Brüsten ${ }^{140}$.

\subsection{Brustkrebs und Brustgeschwüre}

Im Rezept Nr. 20 (S. 63) empfiehlt der Kompilator gegen das Brustgeschwür warmen Schafmist auf die schmerzende Stelle zu legen. Ebenfalls wird die Verwendung von Agrimonia, vermischt mit altem Fett, empfohlen. Vermutlich wurde dem eine weitere Substanz hinzugefügt, jedoch ist die Kopie der Handschrift an dieser Stelle verderbt und auch die Anwendungsform sowie weiteres Vorgehen kann nur vermutet werden. Wahrscheinlich sollten die Substanzen aufgebracht werden, so dass sich das Geschwür eröffnete. Im Anschluss daran wurde die Agrimoniawurzel mit Öl zerstoßen und aufgelegt. Wenn diese Arznei nicht half, empfahl der Kompilator Honig und Butter zu vermischen und auf die Brust zu legen.

Dieses Rezept findet sich ebenfalls im „Speyrer Frauenbüchlein“ wieder, nur im letzten Teil des Rezepts existiert eine Abweichung. Somit könnte die verderbte Form im Codex die Applikationsart und Dauer beinhaltet haben, hier soll Agrimonia mit altem Fett für Tage oder drei Stunden aufgelegt werden, bis dass das Geschwür geöffnet und ausgeflossen ist. Eine ergänzende Substanz zu dem Fett und der Agrimonia wird hier nicht genannt ${ }^{141}$.

Der Schafmist stellt einen Teil der Dreckapotheke dar, welche im Rezept Nr. 40 beschrieben ist. Jühling führt explizit die Wirkung des warmen Schafmists gegen Brustkrebs auf ${ }^{142}$.

Agrimonia Eupatoria L., auch unter dem Namen des Odermenning bekannt, wurde äußerlich als Wundmittel und innerlich gegen Leberleiden, Diarrhoe und Stomatitis angewendet. Er enthält ätherisches Öl und Gerbstoff ${ }^{143}$. Odermenning wurde gegen Krebsleiden und als Analgetikum verwendet. Seine Blätter halfen bei schlecht

\footnotetext{
${ }^{140}$ vgl. Kotsch/ Keil, 2008/ 09, S. 70

${ }^{141}$ vgl Siegmund, 1990, S. 24

142 vgl. Jühling, 1900, S. 156

${ }^{143}$ vgl. Dragendorff, 1967, S. 280
} 
heilenden Wunden und Geschwüren. Der Samen und die Wurzel wirkten leberstärkend ${ }^{144}$.

Über die Anwendungsgebiete des Öls wurde bereits im Rezept Nr. 12 berichtet, die Verwendung des Honigs findet sich im Rezept Nr. 7 und die der Butter im Rezept Nr. 23.

Im Rezept Nr. 21 (S. 64) wird eine Arznei zur Behandlung einer Brustschwellung genannt. Der Kompilator empfiehlt Wachs und Öl zu sieden und daraus ein Pflaster herzustellen, welches im Anschluss daran auf die Geschwulst gelegt werden soll. Wenn diese Verordnung nicht hilft, soll Burgelkraut ${ }^{145}$, mit Rosenöl vermischt, in ein Tuch gegeben und anschließend über die Schwellung gelegt werden.

Galen schreibt dem Wachs eine mittelmäßige Natur zu, es war nicht zu warm, nicht zu kalt, nicht zu feucht und nicht zu trocken und war zu Krankheiten nützlich, welche durch Hitze oder Kälte entstanden. Aus Wachs und Öl bereitete er ein Kühlpflaster, welches beispielsweise gegen Geschwüre benutzt werden konnte. Zur Abkühlung des Wachses benutzte Galen kaltes Brunnenwasser, welches der Kompilator nicht berücksichtigt hat, sofern er beabsichtigte, das Kältepflaster zu verordnen ${ }^{146}$.

Burgel gehört zur Gruppe der Portulaceae, es sind circa 125 Arten bekannt. Das Kraut wurde gegen Hämoptoe, Blasen- und Nierenleiden eingesetzt ${ }^{147}$. Innerlich Angewendet half Burgelkraut gegen Geschwüre des Genitals. Nach Lonicerus, sollte Burgel, als Pflaster zubereitet, bei einer Art entzündeter Geschwulst nützlich gewesen sein, bei der nicht genau klar war, ob sich unterhalb der Geschwulst ein fauliger Prozess abspielte. Ein weiterer Anwendungsbereich war die Behandlung unkeuscher Gelüste oder die Hypermenorrhoe ${ }^{148}$.

Die Verwendung des Rosenöls könnte als schmerzstillende Komponente gewählt worden sein. Weitere Anwendungsgebiete des Öls finden sich im Rezept Nr. 12.

\footnotetext{
${ }^{144}$ vgl. Lonicerus, 1679, S. 453

${ }^{145}$ der Kompilator bezeichnet dies als „Wurgelkraut“, im Vergleich mit anderen Codices findet sich bei

ähnlicher Sachlage die Verwendung des Burgel-bzw.-Burtzelkrauts, vgl. Kotsch/ Keil, 2008/ 09, S. 65

${ }^{146}$ vgl. Lonicerus, 1679, S. 639

147 vgl. Dragendorff, 1967, S. 205

${ }^{148}$ vgl. Lonicerus, 1679, S. 174
} 
Im Rezept Nr. 22 (S. 64) beschreibt der Kompilator die Herstellung einer Arznei gegen das Brustgeschwür, welches härter geworden ist und anfängt zu schmerzen (eitern). Hierzu soll Vogelkraut ${ }^{149}$ zerstoßen und als Pflaster auf die Geschwulst gelegt werden, der Saft des Vogelkrauts soll um die Geschwulst herum aufgetragen werden. Eine weitere Möglichkeit stellten grüne wilde Roßpappeln ${ }^{150} \mathrm{dar}$, die zerstoßen als Pflaster aufgelegt werden sollten. Auf diese Weise sollten die Brüste keine Geschwüre mehr bekommen. Eine andere Möglichkeit war die Verwendung des Mohnsamens, welcher in Regenwasser gesiedet und anschließend in einem Leinentuch drei Tage über die Brust gelegt werden sollte.

Der Kompilator verfasste an anderer Stelle das gleiche Rezept zur Behandlung einer Makromastie (vgl. Rezept Nr. 43). Die Verwendung des Vogelkrauts rechtfertigt den Einsatz bei der Krebstherapie sicherlich mehr, als bei der Behandlung der Makromastie, da diese Pflanze zelltoxische Anteile besitzt und so vermutlich ein Krebswachstum verlangsamt hat. Mehr konnte der Kompilator zu dieser Zeit nicht gewusst haben.

\section{Sexualität}

Die Kirche forderte eine möglichst frühe Verheiratung von Mann und Frau, um eine mögliche außereheliche sexuelle Betätigung zu vermeiden. Aber auch die Ehe war kein Freibrief für ein ungehemmtes sexuelles Leben, sie diente der Zeugung von Nachkommen. Nachdem die fruchtbaren Jahre vorbei waren, sollten Ehegatten die sexuelle Betätigung aufgeben ${ }^{151}$. Wie auch im Kapitel zur Abtreibung zu lesen ist, stellte ein unnötiges Vergießen des Samens für die Kirche eine Sünde dar. Diese Auffassung brachte die damaligen Ärzte in Konflikt mit ihrem medizinischen Wissen. Für sie war der Verlust des Spermas ein natürlicher Drang des Mannes, der dies

\footnotetext{
${ }^{149}$ siehe auch bei Rezept Nr. 43, durch die Erwähnung des Vogelkrauts in anderen Codices, bei gleicher Indikation, wird davon ausgegangen, dass der Kompilator dieses beabsichtigt hatte aufzuführen. Im Codex selbst ist es als „Volkraut" aufgeführt.

${ }^{150}$ siehe bei Rezept Nr. 43, der Kompilator beschreibt die Verwendung von „melden“, im Vergleich mit anderen Codices sind es bei gleicher Indikation die malcen, diese entsprechen der Rosspappel.

${ }^{151}$ vgl. Diepgen, 1937, S. 318
} 
allein der Gesundheit wegen brauchte. Noch mehr aber als der Mann musste die Frau inren Samen loswerden, da dieser durch seine feuchte und kalte Natur bei Zurückhaltung, zur Krankheit führen würde ${ }^{152}$. Die Frau wurde auf ihren Hauptzweck, nämlich den der Fortpflanzung, reduziert. Theologen machten sich dies zu Nutze, um der Frau Schlechtes nachzusagen und bezeichneten sie als ein von ihren Geschlechtsorganen gelenktes Wesen. Der Glaube, sich über das Menstruationsblut mit Lepra zu infizieren, schürte die Angst der Männer ${ }^{153}$.

\subsection{Lustprobe}

Der Kompilator beginnt mit dem Rezept Nr. 41 (S. 72), welches feststellen soll, welche Frau die Männer gerne hat. Hierzu sollen zerstoßene Rüben in einem Leinentuch über die Haut gebunden werden. Findet man nach kurzer Zeit Würmer in den Rüben, konnte man sicher sein, dass die Frau am anderen Geschlecht körperlich interessiert war.

Wurde die Rübe oder deren Samen innerlich angewendet, sollte dies dazu führen, dass der Mensch zur Unkeuschheit getrieben wurde. Dies könnte durch die blähende Eigenschaft der Rübe begründet gewesen sein ${ }^{154}$. Im Mittelalter herrschte der Glaube, dass der Geist der Begierde eine Erektion durch Blähung hervorrief. Man setzte dies in Analogie mit blähenden Speisen, die daher in Religionsgemeinschaften gemieden werden sollten ${ }^{155}$. Die äußerliche Anwendung der Rübe war im Anbetracht dessen, was der Kompilator festzustellen beabsichtigte, sicherlich die richtige Anwendungsform. Vermutlich sollten durch die schmutzigen Gedanken der Frau die Würmer schneller angezogen werden. „Die gleiche Lustprobe ist auch im Traktat Von der Natur der Frauen und ihren Krankheiten überliefert" ${ }^{\text {"156. }}$.

Ebenfalls findet sich dieses Rezept im „Speyrer Frauenbüchlein“ wieder. Der Kompilator dieser Handschrift erklärt den Grund wie die Würmer in das Leinentuch

\footnotetext{
152 vgl. Diepgen, 1937, S. 144

153 vgl. Thomasset, 1993, S. 55- 83

${ }^{154} \mathrm{vgl}$. Lonicerus, 1679, S. 414

${ }^{155} \mathrm{vgl}$. Thomasset, 1993, S. 63

${ }^{156}$ Kruse, 1996, S.152
} 
gelangen folgendermaßen: Waren die Frauen heißer Natur, hatten sie die Männer gerne und Würmer wurden im Tuch gefunden. Wenn sie kalter Natur waren, fand man keine Würmer und die Frauen waren somit nicht am Mann interessiert ${ }^{157}$.

\subsection{Die Behandlungsmethoden der Unkeuschheit}

Im Rezept Nr. 42 (S. 72) empfiehlt der Kompilator für die „verfluchte, tote, unkeusche Seele im Leib“ in selben Teilen, Wermut, Nesseln, Genserich ${ }^{158}$, Giersch ${ }^{159}$, Sadebaum, Beifuß, Schwalbenkraut ${ }^{160}$ und Raute zu zerstoßen und den Saft zu trinken. Eine weitere Möglichkeit stellte der Saft von Betonien ${ }^{161}$ und Grindwurz dar, welcher ebenfalls getrunken werden sollte.

Die Anwendungsbereiche von Wermut, Sadebaum und Raute sind im Rezept Nr. 4, die der Nesseln im Rezept Nr. 17 und die des Beifußes im Rezept Nr. 5 beschrieben.

Der Genserich wirkt austrocknend und zusammenziehend. Innerlich Angewendet half er gegen Aszites, Blutungen und bei vaginalem Ausfluss. Bei Glieder- und Hüftschmerzen wurde er äußerlich als schmerzstillendes Mittel aufgetragen ${ }^{162}$. Herba Anserinae potentillae wirkt krampfstillend und fand bei kolikartigen Diarrhoen seine Anwendung. In der Homöopathie wird es gegen Gelenkentzündungen, Darmerkrankungen und bei Menstruationsbeschwerden verwendet ${ }^{163}$.

Aegopodium podagrariae, oder auch Giersch genannt, wurde als Wundmittel oder gegen Podagra verwendet. Der Giersch wurde auch als das „wilde Geschlecht" des Meisterwurz bezeichnet ${ }^{164}$. Der Meisterwurz wurde zur Vertreibung böser und

\footnotetext{
${ }^{157}$ vgl. Siegmund, 1990, S. 67

158 der Kompilator nennt es „Gerisch“, im Vergleich mit anderen Codices findet sich bei gleicher Indikation die Verwendung von Genserich, vgl. Kruse, 1996, S. 151

${ }^{159}$ bei dem Wort „Gersch“ handelt es sich wahrscheinlich um eine verderbte Form von Giersch.

160 der Kompilator nennt es „Telidonia“, dies ist vermutlich eine verderbte Form von Celidonia, welches das Schwalbenkraut oder Schellkraut darstellt, vgl. Mildenberger, 1997, S. 320

${ }^{161}$ der Kompilator nennt es „Patonig“, es handelt sich wahrscheinlich um eine verderbte Form von Betonie, welche in anderen Codices, bei gleicher Indikationsstellung, aufgeführt wurde , vgl. Kruse, 1996, S. 151

${ }^{162}$ vgl. Mattioli, 1594- 1615, S. 350rA

163 vgl. Hoppe, 1951, S. 171- 172

${ }^{164}$ vgl. Schneider, 1974, S. 49- 50
} 
überschüssiger Feuchtigkeit verwendet. Ebenfalls war er Bestandteil einer Arznei, welche als Emmenagogum Anwendung fand ${ }^{165}$.

Das Schwalbenkraut oder Schwalbenwurz, Chelidonium majus L., wurde zur Herstellung eines „Augenwassers“ verwendet, welches beispielsweise die Augen wieder klar machte ${ }^{166}$. Schwalbenkraut war heißer Natur im vierten Grad und trockener im dritten. Mit Wein gesiedet und getrunken half es gegen Gelbsucht. Weitere Anwendung fand es bei Zahnschmerzen, Aussatz und Fieber. Das Schwalbenkrautwasser wurde zur Heilung von Krebsgeschwüren und Fisteln eingesetzt ${ }^{167}$.

Betonica officinalis L. ist ebenfalls unter dem Namen Zehrkraut oder Pfaffenblümlein bekannt. Die Wurzel fördert den Brechreiz und wirkt reinigend. Das Kraut der Pflanze wurde gegen Blähungen, Blasen-und Nierenleiden eingesetzt ${ }^{168}$. Menschen mit psychischen Leiden oder Epilepsie sollten Bethonien zu sich nehmen. Die Pflanze wirkte emmenagog und gegen Uterusbewegungen. Bethonienwasser wurde gegen Aszites, Gelbsucht (Ikterus) und Fieber eingesetzt ${ }^{169}$. In den altdeutschen Versionen des „Batungentraktats“ fehlt der Hinweis, dass die Pflanze libidomindernde Eigenschaften besa $\beta^{170}$.

Der Grindwurz war vermischter Natur und Komplexion. Dessen Kraut wurde zur Heilung von Geschwüren an den Brüsten und Genitalien verwendet ${ }^{171}$. Der Saft von den Blättern und Wurzeln wurde zur Herstellung einer Grindsalbe benutzt ${ }^{172}$.

Das Rezept Nr. 44 (S.73) beschreibt ebenfalls, wie die Libido einer Frau gemindert werden kann, wenn diese vor unkeuschen Gedanken weder essen noch trinken möchte. Die Kopie des Codex ist an dieser Stelle teilweise verderbt, so dass es möglich ist, dass einige Textstellen nicht vollständig wiedergegeben sind. Zur

\footnotetext{
${ }^{165}$ vgl. Lonicerus, 1679, S. 473- 474

${ }^{166}$ vgl. Mildenberger, 1997, S. 320- 321

${ }^{167}$ vgl. Lonicerus, 1679, S. 373- 374

${ }^{168}$ vgl. Dragendorff, 1967, S. 576

169 vgl. Lonicerus, 1679 , S. 308- 310

${ }^{170}$ vgl. Kotsch/ Keil, 2008/ 09, S. 82

${ }^{171}$ vgl. Mattioli, 1594- 1615, S. 399rA

172 vgl. Lonicerus, 1679, S. 218- 219
} 
Linderung empfiehlt der Kompilator so viel, wie ein Pfennig wiegt, Tausendgüldenkraut ${ }^{173}$ und so viel, wie Silber wiegt, warmes Wasser zu vermischen. Von diesem Trank soll an drei Tagen jeweils ein Napf getrunken werden, dass die böse Last vergeht.

Das Tausendgüldenkraut wurde bei Dioskurides, Plinius, Albertus Magnus und bei Hildegard von Bingen als Heilpflanze beschrieben. Im Mittelalter hieß die Pflanze auch "febrifuga" wegen ihrer fiebersenkenden Eigenschaft. Der Name Centaurea wurde auf "centum aurum" zurückgeführt, was Hundertguldenkraut bedeutete; um eine Steigerung der Heilwirkung hervorzurufen, nannte man es im Verlauf Tausendgüldenkraut ${ }^{174}$. Das Kraut von Erythraea Centaurium Pers. wurde als Digestivum und Antidysentericum verwendet ${ }^{175}$. Es existieren zwei Formen des Tausendgüldenkrautes. Centaurium majus wurde unter anderem gegen Uterusbeschwerden und zur Geburtseinleitung verwendet. Centaurium minus wurde bei Gelbsucht (Ikterus), Lendenschmerzen und Fieber eingesetzt. Der Saft wirkte emmenagog und das Centauriumwasser wurde zur Austreibung einer Todgeburt (missed abortion) verwendet ${ }^{176}$.

Im Rezept Nr. 45 (S. 73) empfiehlt der Kompilator, wie auch im Rezept Nr. 42, die Verwendung von Genserich ${ }^{177}$ bei „ungezogenen Frauen die die Männer so gerne haben“. Dieser soll als Pulver zur Speise gegeben werden. Diese Arznei hilft Frauen wie auch Männern gleichermaßen und sofort.

Die Verwendung des Genserich wurde im Rezept Nr. 42 beschrieben.

\footnotetext{
${ }^{173}$ der Kompilator beschreibt es als „Tauriam“, es handelt sich hierbei vermutlich um die verderbte Form von Centaurium, dem Tausendgüldenkraut.

${ }^{174}$ vgl. Schipperges, 1985, S. 123

175 vgl. Dragendorff, 1967, S. 528

${ }^{176}$ vgl. Lonicerus, 1679, S. 216- 218

177 der Kompilator schreibt „Grenczing“, vermutlich handelt es sich um die verderbte Form von Grensinc, welches dem Genserich entspricht, vgl. Rohland, 1982, S. 420
} 
Im Rezept Nr. 46 (S. 73) wird die Verwendung der Batonie ${ }^{178}$ zur Heilung unkeuscher Krankheit empfohlen. Wer krank von unkeuscher Luft wird, soll Batonie mit warmem Wein oder mit Myrre kochen und dies trinken. Eine weitere Möglichkeit stellt der Erdrauch dar, welcher über die Brust gelegt werden soll.

Die Verwendung der Batonie wurde bereits im Rezept Nr. 42 beschrieben, sowie die des Weins im Rezept Nr. 7. Die Anwendungsgebiete der Myrre finden sich im Rezept Nr. 5.

Der Erdrauch war warmer und trockener Natur im anderen Grad. Innerlich angewendet heilte er Erkrankungen der Leber, Milz und die Gelbsucht (Ikterus) ${ }^{179}$. Weiter wurden der Aszites und der Aussatz mit Erdrauch behandelt ${ }^{180}$.

Die verwendeten Pflanzen in den Rezepten zur Heilung der Unkeuschheit besaßen meist reinigende Eigenschaften auf bestimmte Organsysteme. Vermutlich beabsichtigte der Kompilator durch die Reinigung des Körpers auch die Gedanken zu säubern. Wie im Rezept Nr. 42 zu erkennen ist, wurden ebenfalls die typischen emmenagog wirkenden Pflanzen verwendet, der Kompilator könnte durch ihre Verwendung mögliche Uteruspathologien verhindert haben wollen. Wie bereits im Kapitel Nr. 4.2 der Uteruspathologien zu lesen ist, war regelmäßiger Geschlechtsverkehr indiziert, wenn man diesem entsagen wollte, musste jedoch eine mögliche resultierende Erkrankung vermieden werden.

\footnotetext{
${ }^{178}$ der Kompilator schreibt wie auch im Rezept Nr. 42 „Patonig“, auch hier wird im Vergleich mit anderen Codices die Batonie als die gemeinte Pflanze verstanden. Vgl. Kruse, 1996, S. 151

${ }^{179}$ vgl. Mattioli, 1594- 1615, S. 407rB

${ }^{180}$ vgl. Lonicerus, 1679 , S. 375
} 


\section{Schwangerschaft}

\subsection{Empfängnis}

„Nach Soran ist der Orgasmus der Frau zum Zustandekommen der Befruchtung unerlässlich“"181. Für die Hippokratiker ist der Frühling die beste Zeit, um schwanger zu werden, für Aristoteles hingegen ist es der Januar und Februar. Im Konzeptionsoptimum waren sich alle einig, dieses war in den ersten Tagen nach der Menstruation, oder wenn diese anfing nachzulassen. Zu diesem Zeitpunkt war der Muttermund geöffnet und die Gebärmutterwand rau, so dass das Sperma die besten Möglichkeiten hatte einzudringen und gehalten zu werden ${ }^{182}$. Frauen zwischen dem fünfzehnten und zwanzigsten Lebensjahr wurden als geschlechtsreif betrachtet. Bei innen waren das Gefäßsystem und die Geschlechtsorgane soweit herangereift, dass sie den Samen aufnehmen, behalten und erwärmen konnten. Eine Befruchtung vor Vollendung der Reife brachte eine kränkliche Frucht hervor ${ }^{183}$. Um die Entwicklung des Embryos oder des Föten zu verstehen und beschreiben zu können, zog man den Vergleich mit der Natur und dem Tierreich heran. Der Vergleich zwischen der Mutter und dem Ackerboden trug dazu bei, dass es verständlich wurde die Gesundheit der Mutter zu schützen, da diese wesentlich zur Gesundheit des Kindes beitrug ${ }^{184}$. Der Kompilator der römischen Handschrift beschreibt im Rezept Nr. 28 (S. 67), welche Konstitution bei der Frau eine Schwangerschaft unmöglich machte und im Abort endete. So sollten Geschwüre innerhalb der Gebärmutter und ein zu dünner Körper dazu führen, dass sie ihr Kind verliert oder selbst verstirbt. Auch die Frauen, die nicht krank sind, jedoch einen geschwächten Leib haben, werden ihr Kind im nächsten bis spätestens im dritten Monat verlieren. Weiter beschreibt der Kompilator den Normalbefund. Die Gebärmutter soll vollständig mit dem Samen des Mannes gefüllt sein, wenn die Frau das Kind austragen möchte. Eine verschlossene Gebärmutter zeigte das Vorliegen einer Schwangerschaft, war diese geöffnet war die Frau nicht schwanger.

Der Scholastiker Gilles de Rome beschrieb den weiblichen Samen als etwas uneigentliches, dieser war für inn zur Zeugung nicht notwendig. Der weibliche Samen

\footnotetext{
${ }^{181}$ Diepgen, 1937, S. 145

${ }^{182}$ vgl. Diepgen, 1937, S. 145- 146

${ }^{183}$ vgl. von Bingen, 1957, S. 179

184 vgl. Diepgen, 1937, S. 148
} 
erfüllte für inn lediglich nebensächliche Aufgaben wie das Anfeuchten beim Geschlechtsverkehr und das Leiten des Samens in die Gebärmutter. Durch seine mangelhafte Kochung wirkte er kühlend auf das heiße Sperma des Mannes, damit dieses, ohne zu verdampfen, den Uterus vollständig ausfüllen konnte. Der Verfasser der "Secreta Mulierum" leitet den Geschlechtstrieb der Frau von Gilles` Wärmetheorie ab. Durch den Wärmemangel der Frau fordert ihre Gebärmutter förmlich das heiße Sperma des Mannes ${ }^{185}$.

Der Kompilator der Handschrift beschreibt im Rezept Nr. 33 (S. 69) die Besonderheit des Spermas und gibt inm im Gegensatz zum weiblichen Samen eine Sonderstellung. Im Mann existierten zwei verborgene Wege, durch den einen gelangt die Speise, durch den anderen der Samen. Letzterer verläuft wie auch das Blut von dem Gehirn zu den Ohren, von dort durch sämtliche Adern in das Mark und zu den Lenden. Genährt wird der Samen auf dem Weg in das Gehirn, und sollte er den richtigen Weg finden, erhält er an letzter Stelle seine Farbe. Um den besonderen Samen nicht zu schädigen, sollen sich die Männer, genau wie Schwangere, vor Frost, Rauferei, Fasten und Geschrei hüten.

Im Falle einer erfolgreichen Zeugung bestand die Möglichkeit eines Schwangerschaftstests, wie der Kompilator im Rezept Nr. 24 (S. 65) beschreibt. Man sollte der Frau Met und Milch zu trinken geben, leidet sie anschließend an Bauchschmerzen, konnte man sicher sein, dass sie schwanger ist. Oder der Urin der Frau soll auf wilde Pappeln gegossen werden, wenn diese grün bleiben, ist die Frau schwanger. Eine weitere Möglichkeit war, den nächtlichen Urin in einer Schüssel zu sammeln und eine stählerne Nadel hinein zu legen. Wenn die Frau schwanger ist, legt sich Schleim unten um die Nadel, wie es auch die Hefen tun.

${ }^{185}$ vgl. Hippéli/ Keil, 1982, S. 71- 72 


\subsection{Abtreibung}

Wesentliche Schwierigkeiten brachte die Festlegung der Beseelung des Fötus und damit verbunden die Konsequenzen einer Abtreibung mit sich. „homo est et qui est futurus et fructus omnis iam in semine est"186, sagte Tertullian und sah den Sitz der Seele im menschlichen Samen. Somit war für ihn bereits die Empfängnisverhütung eine Sünde. Während nach christlicher Auffassung bezüglich Abtreibung und Empfängnisverhütung Klarheit herrschte, machte man sich Gedanken um den Zeitpunkt, wann eine Abtreibung als Todschlag zu bewerten war. Der vierzigste Tag wurde in Anlehnung an die jüdische Rechtsüberlieferung als Richtwert benutzt. Eine Änderung der Frist wurde im frühen dreizehnten Jahrhundert vorgenommen. Johannes Teutonicus erklärte, dass die Seele eines Mannes früher eingegossen wird. Das kanonische Abtreibungsverbot erhielt eine geschlechtsspezifische Änderung, für Jungen behielten die vierzig Tage bestand, für die Mädchen wurden achtzig Tage veranschlagt. Der Arzt Avicenna nennt als Möglichkeit, einen Fruchtabgang zu erzeugen, häufigen Geschlechtsverkehr, Blähungen und Überfeuchtungen des Muttermunds, Schläge und Sprungtechniken. Aber auch die Anwendung von Kräutern, Tränken und Fußbädern wurden in der Literatur beschrieben ${ }^{187}$.

\subsection{Die Entwicklung des Föten}

Das Geschlecht des Kindes wurde durch mehrere Faktoren beeinflusst. Nach Ansicht der Hippokratiker war die Qualität des Samens ausschlaggebend und auch die Lage im Uterus entschied das Geschlecht ${ }^{188}$. Nach Galenos von Pergamon entstanden auf der rechten Seite die Knaben, da hier durch die Nähe zur Leber mehr Wärme vorhanden sei. Auf der linken Seite wuchsen die Mädchen heran, die unausgereifte Knaben darstellten, da die Geschlechtsteile noch innerlich lagen ${ }^{189}$.

\footnotetext{
${ }^{186}$ Jerouschek, 1993, S. 47

${ }^{187}$ vgl. Jerouschek, 1993, S. 47- 62

188 vgl. Diepgen, 1937, S. 154

${ }^{189}$ vgl. Fischer- Homberger, 1984, S. 128
} 
Neben den Wirkkräften des männlichen Spiritus stellten für Gilles de Rome die Planeten einen Einflussfaktor in der Keimentwicklung dar. Er beschrieb sie am Modell von Dorotheus. Dies ergab eine Siebenerreihe, die mit dem Saturn begann, welcher die Samenflüssigkeit gerinnen ließ und mit dem Mond endete, welcher die Keimentwicklung zum Abschluss brachte. Jedoch erwähnte er ein weiteres Modell der Keimentwicklung, welches über fünf Stufen verlief und nach vierzig Tagen mit der Entwicklung der Gliedmaßen und einem vollständig ausgebildeten Fötus endete. Für die Beschreibung der Geschlechtsbestimmung benutze Gilles das Modell des siebenkammerigen Uterus ${ }^{190}$.

\subsection{Unfruchtbarkeit}

Die Sterilität einer Frau stellte ein wichtiges Thema in der Medizin dar. Kinderlosigkeit bedeutete schon immer Defekt und Unglück. Blieb eine Ehe kinderlos, konnte sie wieder geschieden werden. Im Corpus hippocraticum wurden die Ursachen einer Unfruchtbarkeit bei Männern und Frauen beschrieben. Die Sterilität eines Mannes konnte durch seine Konstitution, genitale Anomalien, Spermaanomalien oder Impotenz gegeben sein. Bei der Unfruchtbarkeit einer Frau waren Adipositas, Störungen der Menstruation oder eine falsche Temperierung des Uterus als Ursache beschrieben ${ }^{191}$. Das Rezept Nr. 31 (S. 68) beschreibt die unterschiedliche Beschaffenheit der Gebärmutter. So ist eine kalte und dichte Gebärmutter nicht geeignet, einen Nachkömmling zu empfangen, die nasse und feuchte Gebärmutter kann den Samen nicht halten, eine heiße und trockene Gebärmutter kann ebenfalls keine Schwangerschaft empfangen. Nur wer das richtige Maß an allem hat, kann schwanger werden. Vermutlich mit dem Wissen, dass die Adipositas der Frau eine Ursache der Unfruchtbarkeit darstellt, hat der Kompilator in seiner Rezeptsammlung eine „Diät" aufgenommen. Im Rezept Nr. 19 (S. 62) empfiehlt er bei „dicken“ Frauen zwei libra ${ }^{192}$ Wermut und einundzwanzig lot ${ }^{193}$ Cenemus $^{194}$ vom dritten Teil acht lot

\footnotetext{
${ }^{190}$ vgl. Hippéli/ Keil, 1982, S. 74- 75

${ }^{191}$ vgl. Diepgen, 1937, S. 199- 200

192 das Medizinalpfund Libra enthielt 12 Unzen, welches 360 Gramm entsprach, vgl. Flatow, 1932, S. 1808

19324 Lot entsprachen um 1555 nach Nürnberger Gewicht 357,66g, ein Lot entsprach ca. 14,9g, vgl. Schmitz, 1998, S. 447
} 
Kürbis von dem neunten Teil drei lot Senf zu verwenden ${ }^{195}$. Diese sollen in Wasser vermischt und der Frau zu trinken gegeben werden, so dass sie dünner wird. Ein weiteres erprobtes Mittel stellt die Krötenkrautwurzel dar, welche getrocknet und anschließend zerstoßen mit Wein oder Wasser getrunken werden soll. Zeitgleich soll ein gesegnetes Brot vor den Mund und die Nase gehalten werden. Die darauffolgende Darmentleerung reinigt diejenigen, welche einen festen Leib oder Bauch haben.

Die Verwendung des Wermuts wurde bereits im Rezept Nr. 4 beschrieben.

Der Kürbis, Cucurbita Pepo L. enthält in seinem Saft 1,6\% Dextrose und 0,9\% Rohrzucker. Der Samen enthält 33\% fettes Öl und wird zur Ölzubereitung und als Mittel gegen den Bandwurm eingesetzt ${ }^{196}$. Als weiteres wurde der Samen bei Milz und Leberleiden verwendet. Der Kürbis war das klassische Abführmittel. Das Wasser des unreifen Kürbisses wurde bei Fieber und entzündeten Geschwüren angewendet. Der wilde Kürbis, Colocynthis, sollte nur im Beisein eines Arztes verwendet werden, da er giftige Eigenschaften besitzt. Er war heiß im dritten Grad und trocken in einem anderen. Eine Überdosierung des Colocynthis wirkt herz- und leberschädigend, stuhl- und urintreibend. Apotheker minderten die Giftwirkung durch die Zugabe von Mastix $^{197}$. Von den Griechen wurde der gummiartige Saft des Mastixbaumes, Mastix genannt ${ }^{198}$.

Senf existiert in mehreren Varianten. Der schwarze Senf, Sinapis nigra L., enthält myronsaures Kali, Sinapin und ÖI. Im ÖI findet sich Glycerid der Eruca- Säure. Der weiße Senf, Sinapis alba L., enthält Sinalbin und im Öl Brassicasäure. Der Samen beider Senfarten wirkt durchblutungsfördernd, der weiße jedoch in schwächerer Form ${ }^{199}$. Lonicerus unterscheidet den gelben und den weißen Senf, beziehungsweise Wassersenf. Der Samen des gelben Senfs war warm und trocken im vierten Grad. Unter anderem wurde er zur Verdauungsförderung und als Aphrodisiakum eingesetzt, ebenfalls heilte er Geschwüre und das Gehirn von „böser

\footnotetext{
${ }^{194}$ bei „Cenemus" handelt es sich wahrscheinlich um eine nicht deutbare Substanz, die Vermutung, dass es sich um eine verderbte Form von cenatus, welches nach dem Essen bedeutet, vgl. Menge, 1988, S. 116, handelt, wurde verworfen, da dies im Rezept keine sinnvolle Ergänzung ergab.

${ }^{195}$ hinsichtlich der Mengenangabe "dritte Teil" und "neunte Teil" handelt es sich vermutlich um eine sprachliche Verballhornung, die Mengenangaben können in keine sinnvolle Reihenfolge gebracht werden.

${ }^{196} \mathrm{vgl}$. Dragendorff, 1967, S. 652

${ }^{197}$ vgl. Lonicerus, 1679 , S. $442-443$

${ }^{198}$ vgl. Lonicerus, 1679, S. 131

${ }^{199}$ vgl. Dragendorff, 1967, S. 256
} 
Feuchtigkeit“. Der weiße Senf besaß die gleiche Natur wie auch der Gelbe. Er wirkt laktogen, diätetisch und gegen Geschwülste der Brust und des Genitals. Der Wassersenf wirkt karminativ, magenstärkend und verdauungsfördernd ${ }^{200}$.

Das Krötenkraut entspricht der Schartenblume. Den Namen Krötenkraut bekam die Pflanze, weil sich in ihrer Nähe Kröten und andere Tiere aufhielten, um sich zu schützen oder durch diese Heilung zu erlangen. Das Kraut wirkt kühlend und trocknend. Es wurde zur Behandlung von Magenbeschwerden, Mastdarmerkrankungen und Geschwüren eingesetzt ${ }^{201}$.

Im Rezept Nr. 32 (S. 69) wird die mangelnde Zeugungsfähigkeit des Mannes beschrieben. Wenn der Samen des Mannes zu dickflüssig ist, reicht er zur Zeugung nicht aus. Genauso wird der zu dünne Samen zur Zeugung nicht fähig sein, da er zu früh und nicht am rechten Ort vergossen wird.

Im Rezept Nr. 6 (S. 57) beschreibt der Kompilator unter der Rubrik „dolor matricis“, mögliche Pathologien welche verhindern, dass eine Schwangerschaft entsteht oder aufrecht erhalten werden kann. Er beschreibt, dass durch das Menstrualblut oder durch zu viel Fett in der Gebärmutter das Kind erstickt. Eine fehlende Vereinigung, vermutlich zwischen dem Menstrualblut und dem Samen des Mannes, oder die fehlende Fruchtentwicklung wird hier als Ursache aufgeführt. Zur Besserung empfiehlt der Kompilator, grüne Raute zu zerreiben und dies an die Gebärmutter zu stoßen. Zudem soll Schwefel mit starkem Essig vermischt, anschließend über die Nase eingeatmet und ein Teil davon wiederum an die Gebärmutter gebracht werden.

Der Kompilator verwendete in seinem Rezept die Raute, um vermutlich überschüssiges Menstrualblut zu entfernen. Die Verwendung der Raute wurde

\footnotetext{
${ }^{200}$ vgl. Lonicerus, 1679 , S. 370- 372

${ }^{201}$ vgl. Lonicerus, 1679, S. 243
} 
bereits im Rezept Nr. 4 beschrieben. Die Anwendung des Schwefels ist im Rezept Nr. 9 und die Verwendung des Essigs im Rezept Nr. 26 beschrieben.

In dem Rezept Nr. 25 (S. 65) wird ein Test zur Feststellung der Fruchtbarkeit einer Frau aufgeführt. Hierzu sollte man drei Bohnen in den Urin legen, der nach Mitternacht gesammelt wurde. Die Bohnen sollten für drei Tage und drei Nächte darin verweilen und anschließend gesetzt werden. Wenn die Bohnen innerhalb von sechs Tagen Triebe bildeten und zu wachsen begannen, dann war es möglich, der Frau zu einer Schwangerschaft zu verhelfen. Geschah dies jedoch nicht, so gab es keine Hilfe mehr. Eine weitere Möglichkeit zur Testung der Fruchtbarkeit war es, Gerstenkörner für einen Tag und eine Nacht im Urin liegen zu lassen und anschließend genau wie bei den Bohnen zu verfahren.

In weiteren Rezepten schreibt der Kompilator unter der Rubrik „Von den weiben vnd bermuter" einzelne Theorien bezüglich der Schwangerschaft zusammen. Das Rezept Nr. 27 (S. 67) beschreibt generelle Dinge zur Schwangerschaft. Im ersten Teil geht es um die Anzeichen einer erfolgreichen Zeugung, wenn einer Frau die Gebärmutter schwillt, sich diese leicht erhebt und sie zuvor viel Verkehr hatte, konnte sie sicher sein, dass sie schwanger war. Als nächstes schließen sich die Symptome bei drohendem Abort an. Hierbei sollten sich die Brüste während der Schwangerschaft verringern oder eine Brust kleiner werden als die andere. Der letzte Teil im Rezept beschreibt den Milchfluss nach der Entbindung und dass dieser durch das Blut (Lochien) verdorben werden kann.

Das Rezept Nr. 29 (S. 68) beinhaltet mögliche Pathologien und physiologische Veränderungen der Brustdrüse während der Schwangerschaft auf. Der Milchfluss während der Schwangerschaft sollte eine kränkliche Frucht vorhersagen. Hingegen 
waren verschlossene Brüste ein gutes Zeichen für eine gesunde Frucht. Wenn sich zur Zeit der Schwangerschaft die Brüste verringern oder verhärten, kommt es zu Schmerzen in der Brust, in den Lenden, in den Knien und in den Augen, diese Schmerzen sind auch für die Geburt hilfreich. Jedoch soll die Frau die Schwangerschaft vollständig austragen.

\subsection{Der Abort}

Im Rezept Nr. 39 (S. 71) beschreibt der Kompilator eine Medikation um das ungeborene, tote Kind aus dem Mutterleib zu entfernen, wenn es von selbst nicht kommt (missed abortion). Die Frau soll hierzu Frauenmilch mit Öl gemischt trinken oder Myrre mit Wein mischen und dies zu sich nehmen. Danach soll es ihr besser gehen und sie entbindet das Kind.

Die Wirkung der Frauenmilch wurde bereits im Rezept Nr. 10 beschrieben, ihre besondere Heilwirkung war in diesem Fall wahrscheinlich durch den Kompilator gewählt worden um die tote Frucht auszustoßen. Das Öl, im Rezept Nr. 26 zu finden, und auch die Myrre, im Rezept Nr. 5 nachzulesen, sollten wahrscheinlich nach dem Ausstoßen der Frucht zusammenziehend auf den Uterus wirken um eine überschüssige Blutung zu vermeiden. Die Verwendung des Weins ist im Rezept Nr. 7 zu finden.

\subsection{Die Geburt}

Nach circa 267 Tagen endet die Schwangerschaft. Nach damaliger Berechnung entsprach dies vierzigmal die Siebentagefrist der Woche erlebt zu haben. Zur Schwangerschaftsdauer kennen die Hippokratiker das Sieben-, Acht-, Neun-, Zehnund Elfmonatskind. Das Siebenmonatskind war lebensfähig, wenn es die anschließenden vierzig Tage überstand. Das Siebenmonatskind entging den Gefahren des Stürzens im Mutterleib, da es danach sofort entbunden wurde. Das 
Stürzen bezeichnete die Wendung des Kindes im Mutterleib von der Beckenlage in die Schädellage, indem die Eihäute am Nabel abrissen. Das Achtmonatskind hingegen musste nach dem Stürzen im Mutterleib bleiben und zudem alle Gefahren durchmachen, die im achten Monat sowieso auf das Kind einwirkten. Es kam geschwächt auf die Welt und konnte den Umwelteinflüssen nicht standhalten. Es war nicht lebensfähig. Der achte Monat wurde generell, wie auch der vierte, als gefährlicher Zustand für den Fötus beschrieben. Das Neunmonatskind, wenn es am Ende der neun Monate geboren wurde, sowie das Zehnmonatskind, waren für das Leben am besten vorbereitet. Elfmonatskinder entstanden, wenn die Berechnung des Monats mit dem Neumond begann ${ }^{202}$. Die Beeinflussung des Keims durch die Planeten, sollte an dieser Stelle noch einmal erwähnt werden. Im achten Monat der Schwangerschaft nahm nach dem Planetenmodell der kalte Saturn Einfluss auf das Kind. Dies führte dazu, dass das Kind erstarrte. Wurde das Kind entbunden, starb es innerhalb von acht Tagen. Der neunte Monat stand unter der Herrschaft des Jupiters, welcher die Ernährung des Kindes steigerte. Wurde es zu dieser Zeit entbunden, war die Geburt leicht und das Kind hatte eine gute Lebenserwartung. Ab dem zehnten Monat war der Mars vorherrschend, dieser entzog der Frucht die Feuchtigkeit und sorgte für eine erschwerte Geburt ${ }^{203}$.

Nach Hildegard von Bingen sollten Frauen mit schlechten Säften, die beispielsweise unter Gicht litten, Schwierigkeiten bei der Entbindung haben. Sie bekamen die Kinder unter größten Schmerzen. Dies geschah, wenn sich die schützende Hülle mit dem Kind öffnete (Blasensprung) und so die Säfte in eine Art Sturm gerieten und die Geburtswege durch eine Anschwellung verlegt waren. Auch die Fettleibigkeit der Frauen sollte die Geburtswege verlegen. Hildegard von Bingen rät von einer Arzneigabe unter der Geburt bei Verlegung des Geburtskanals ab. Eine Arznei, die überschüssige Säfte abdampfen ließe führe dazu, dass durch den Rauch und die Dämpfe das Kind erstickt. Die besten Voraussetzungen für eine unkomplizierte Geburt erfültten Frauen die nicht krank, nicht zu dünn oder zu dick waren. Den jedoch physiologisch festgesetzten Geburtsschmerz erlitt jede Frau. Stand nun die Geburt unmittelbar bevor, trat das Kind mit einem Blutschwall aus. Nur der Schleim und der Gestank blieben in der Frau und traten erst mit der Periode aus (Lochien). Im Rezept Nr. 30 (S. 68) wird diese Art des Blutflusses, der vor der Entbindung eintrat,

\footnotetext{
202 vgl. Diepgen, 1937, S. 159- 163

${ }^{203}$ vgl. Hippéli/ Keil, 1982, S. 74- 75
} 
folgendermaßen beschrieben. Wenn die Menstruation in Fülle kommt, wird die Frau sehr krank, so wie wenn sie ihr nicht kommt. Diese Art der Gebärmutterkrankheit gilt als Menstruation der schwangeren Frau und zeigt an, dass ein gesundes Kind kommt.

Die Dauer der Reinigung (Lochien) wurde durch die Konstitution der Frau gegeben. War sie trockener Natur, so litt sie nicht unter einem Säfteüberschuss und die Reinigung war in kurzer Zeit abgeschlossen. Bei Frauen, die feuchter Natur waren, brauchte der Körper länger zur Reinigung ${ }^{204}$.

Galen schrieb dem Uterus austreibende Kräfte zu. Er verglich den Geburtsakt mit dem Stuhlgang. Bei der Kontraktion des Uterus ziehen sich alle Wände zusammen und der Fundus tritt tiefer, so wurde das Kind ausgetrieben. Galen sieht in der Anwendung der Bauchpresse, nachdem der Muttermund vollständig geöffnet war, das Mitwirken der Gebärenden. Nach Galen war der Kopf des Kindes das bestmögliche Organ, welches als erstes den Geburtskanal passierte, um den anderen Kindsteilen den Weg durch das Becken zu ermöglichen ${ }^{205}$.

\subsection{Rezept zur Geburtserleichterung}

Im Rezept Nr. 11 (S. 59) beschreibt der Kompilator die Herstellung eines Pflasters zur Linderung des Geburtsschmerzes. Dieser sei daran zu erkennen, dass die Frau über starke Rücken-und Bauchbeschwerden klagt. Zur Besserung der Beschwerden soll Kalk aus gebrannten Kieselsteinen und Seife in einem hölzernen Gefäß vermischt und anschließend zu einem Pflaster verarbeitet und auf die schmerzende Stelle aufgelegt werden.

Der Kalk war warmer und trockener Natur, er wurde zur Heilung von Wunden und Hauterkrankungen verwendet ${ }^{206}$. Kalkwasser wurde bei Schmerzen der Lenden und Füße empfohlen ${ }^{207}$.

\footnotetext{
${ }^{204}$ vgl. von Bingen, 1957, S. 181- 182

${ }^{205}$ vgl. Diepgen, 1937, S. $165-168$

${ }^{206}$ vgl. Lonicerus, 1679 , S. 713
} 
Die Seife könnte als Trägersubstanz und Pflastergrundlage gedient haben.

\subsection{Heil- und Segenssprüche}

Innerhalb der gynäkologischen Rezeptsammlung des Kompilators finden sich keinerlei Beschreibungen des Geburtsaktes mitsamt seiner möglichen Pathologien. Auch die Nachgeburtsperiode findet keinerlei Erwähnung. Über letztere schwiegen sich ebenso die Gelehrten aus. Die Geburt der Plazenta wurde als selbstverständlich angesehen ${ }^{208}$. In der Rezeptsammlung finden sich lediglich Sprüche, die während der Entbindung gelesen oder geschrieben werden sollten. Im Rezept Nr. 36 (S. 70) wird ein Spruch empfohlen, um der Frau eine sanfte Entbindung zu ermöglichen. Auf einem Brief sollten die Worte "Septem dormentes maximianus machus moranonuis dromsius iohannes seraphion constanaus" geschrieben und der Frau um den Bauch gebunden werden. Hatte die Frau entbunden, sollte ihr der Brief schnell abgenommen werden, da sie sonst alles verlor, was sie in oder bei sich hatte. Der oben beschriebene Heilspruch stellt eine Aneinanderreihung von Worten dar, lediglich der Glaube daran konnte die Wirkung erzielen. Im Rezept Nr. 37 (S. 70 ) liest man von einer Zeremonie, die ebenfalls zur Geburtserleichterung eingesetzt werden sollte und als erprobtes Verfahren bezeichnet wurde. Der Kompilator empfiehlt vier Kerzen um die Frau herum aufzustellen, dazu sollte man Weihrauch, Myrre und Gold haben. Vor jeder Kerze soll niedergekniet und das Evangelium gesprochen werden. „In principio erat verbum“, nun sollte eine Kollekte erfolgen, „concede quesum omnipotens deus ut N vnignite filij“. Diese Prozedur sollte bei allen Kerzen wiederholt werden. In kurzer Zeit danach entbindet die Frau. Innerhalb dieser Rezepte erkennt man eher den christlichen als den medizinischen Bezug des Kompilators, welcher in Anlehnung an die Geburt Christi, Gold, Weihrauch und Myrre verwendete ${ }^{209}$. Möglicherweise erhoffte er durch diese Art der Zeremonie die Geburt unter Gottes Segen zu stellen.

\footnotetext{
${ }^{207}$ vgl. HWdA, 1931/ 1932, Band IV, Sp. 935

${ }^{208}$ vgl. Diepgen, 1937, S. 168

209 vgl. Matthäus 2, Vers.11, (Die Bibel 1985)
} 
Im Rezept Nr. 38 (S. 71) wird die Verwendung von Eiswasser zur Entbindung empfohlen. Die Frau soll durch die Verwendung schonend und zügig entbinden. Eine Applikationsform wird durch den Kompilator nicht beschrieben. Eine weitere Möglichkeit stellt die Verwendung von Hundemilch mit Honig gemischt dar, wonach die Frau ebenfalls zügig entbindet.

Die Gabe von Eiswasser wurde vermutlich zur Öffnung des Muttermundes gegeben. Das post partum auftretende Frösteln wurde als Abkühlung des gesamten Körpers verstanden, welches die Frau unter der Entbindung erleben sollte. Galen setzte dies mit der Öffnung des Muttermundes bei der Menstruation gleich ${ }^{210}$.

Auf die Anwendungsgebiete der Milch wurde bereits im Rezept Nr. 10 eingegangen. Hundemilch wurde in der Volksmedizin als Haarwuchsmittel und gegen Flechten eingesetzt ${ }^{211}$. Die Gabe von Hundemilch mit Honig findet sich in anderen Rezeptbüchern zur Austreibung einer Totgeburt ${ }^{212}$.

Die Verwendung des Honigs wurde bereits im Rezept Nr. 7 beschrieben.

\section{Das Wochenbett}

\subsection{Lochien}

Die Lochien wurden als Reinigungsprozess verstanden. Der Körper entledigte sich von Restbeständen, welche der Fötus während der Schwangerschaft von dem Blut der Mutter übriggelassen hatte und welche bis zum Ende der Entbindung im Gefäßsystem der Frau gespeichert wurden. Nach den Hippokratikern dauerte der Lochialfluss nach der Geburt eines Jungen 30, nach der eines Mädchens 42 Tage.

\footnotetext{
${ }^{210}$ vgl. Diepgen, 1937, S. 168

${ }^{211}$ vgl. HWdA, 1931/ 1932, Band IV, Sp. 481

${ }^{212}$ vgl. Kruse, 1996, S. 199
} 
Für sehr gefährlich hielten die Hippokratiker eine vorzeitige Unterdrückung der Lochien ${ }^{213}$.

\subsection{Entstehung der Muttermilch}

Muttermilch und Menstruationsblut zählten als verwandte Produkte des Stoffwechsels. Für die Hippokratiker sorgte der gravide Uterus dafür, dass das Fett der Nahrung in das Netz und das Gekröse gepresst wurde und sich in den Gefäßen des Uterus und der Mammae sammelte. Durch die Wärme des Uterus wurde die Milch süß und stand für den Fötus zur Verfügung. Alles was von ihm nicht verbraucht wurde, sammelte sich in den Brüsten. Zum Milchaustritt aus den Brüsten kam es erst nach der Geburt. Ihnen wurde eine passive Rolle bei der Milchbildung zugesprochen. Erst der Saugakt des Kindes sorgte dafür, dass die Milch aus der Bauchhöhle gefördert wurde. Bei Galen ist es die Brustdrüse, welche aus ihrem zufließenden Material die Milch bildet. Die Vormilch (Colostrum), welche unmittelbar post partum produziert wird, ist inm bekannt und wurde als dünneres Produkt zur Hauptmilch beschrieben ${ }^{214}$. Nach Hildegard von Bingen beeinflusste die Schwangerschaft die Gefäßverbindungen im Körper der Frau. Bei einer nicht Schwangeren war im Bereich des Nabels ein Gefäßgeflecht, welches die Brüste und den Uterus miteinander verband. Bis zum Beginn der Menarche wurden die Brüste mehr genährt um zu wachsen. Durch die Empfängnis wurde das Monatsblut gehalten und kleine Gefäße zu den Brüsten geöffnet. Über die offene Gefäßversorgung wurden die Brüste und die Gebärmutter mit dem Nahrungssaft versorgt. Nach der Entbindung verschlossen sich die zur Gebärmutter führenden Gefäße. Die Gefäße zu den Brüsten blieben geöffnet, um die Milch zu bilden. Die Milchbildung blieb so lange erhalten, wie auch das Kind gestillt wurde, und so lange waren auch die Gefäße zu der Gebärmutter verschlossen ${ }^{215}$.

\footnotetext{
${ }^{213}$ vgl. Diepgen, 1937, S. 169

${ }^{214}$ vgl. Diepgen, 1937, S. 169- 170

215 vgl. von Bingen, 1957, S. 183- 184
} 


\subsection{Förderung des Milchflusses}

Im Rezept Nr. 23 (S. 65) wird eine Arznei beschrieben, welche einer Frau gegeben werden kann, wenn sie zu wenig Milchfluss hat. Sie soll hierzu grünen Fenchel in Wein oder Milch sieden und dies nüchtern so viel und häufig wie möglich trinken. Eine weitere Möglichkeit war das Trinken von Butter mit warmem Wein oder der Verzehr von Lattich mit Essig. Die Verwendung von Frauenmilch mit Fenchelsamen wird ebenfalls empfohlen.

Der Fenchel, auch als Foeniclum vulgare Mill. bezeichnet, enthält ätherisches Öl mit flüssigem Anethol und Fenchon. Die Wurzel wurde als Diuretikum eingesetzt. Das Kraut des Fenchels wurde äußerlich bei einer Entzündung der Mammae und innerlich bei Ikterus und Menstruationsstörungen verwendet ${ }^{216}$. Der Fenchel galt als heiß und trocken in einem anderen Grad. Zur Herstellung einer Arznei wurden Samen, Kraut, Rinde und die Wurzel verwendet. Die lactogene Eigenschaft wurde von stillenden Frauen genutzt. Weitere Anwendung fand der Fenchel bei Brustgeschwüren und Wunden ${ }^{217}$. Auch heute noch ist der Fenchel Bestandteil eines Tees zur Unterstützung des Milchflusses, welcher von Hebammen empfohlen wird ${ }^{218}$.

Butter wurde wie auch das Öl bei der Arzneiherstellung verwendet. Sie wirkt verdauungsfördernd, gegen Meteorismus und fand Anwendung in der Behandlung von Wunden und Geschwüren. Butter wurde in der Neugeborenenpflege verwendet und war wirksam gegen Zahnungsbeschwerden ${ }^{219}$. Die Butter wurde bereits in der Antike als reinigende Substanz und als Fruchtbarkeitssymbol angesehen. In der Volksmedizin stillte sie Hunger und Durst und verlieh besondere Kräfte. Nur die Griechen hielten sie für schädlich ${ }^{220}$.

Der Lattich, auch als Lactuca sativa L. bezeichnet, enthält Lactucin, Lactucopikrin und Lactucerin und ein atropinartiges Alkaloid. Die Blätter, Früchte und der Milchsaft wurden wie auch der Lactuca virosa L. als Hypnotikum, Antitussivum und gegen Herzklopfen eingesetzt ${ }^{221}$. Der Lattich war feuchter und kalter Natur im anderen

\footnotetext{
${ }^{216}$ vgl. Dragendorff, 1967, S. 491- 492

${ }^{217}$ vgl. Lonicerus, 1679 , S. $481-482$

${ }^{218}$ vgl. Lothrop, 2009, S. 206

${ }^{219}$ vgl. Lonicerus, 1679, S. 576- 577

${ }^{220}$ vgl. HWdA, 1927, Sp. 1756- 1757

${ }^{221}$ vgl. Dragendorff, 1967, S. 691
} 
Grad. Nach Lonicerus soll der Verzehr von ungekochtem Lattich schädlich sein. Eine Überdosierung von Lattich senkt die Libido und somit war er als Keuschheitsmittel einsetzbar. Lattichsamen und das Lattichwasser wirken laktogen. Der Lattich wurde unter anderem bei Geschwüren, Aszites und Fieber verwendet ${ }^{222}$.

Wie bereits im Rezept Nr. 10 beschrieben, war die Frauenmilch die wertvollste zur Heilung von verschiedenen Krankheiten. Der Milch wurde allgemein eine nahrhafte Eigenschaft zugeschrieben. Sie wurde innerlich zur Reinigung des Körpers angewendet, Geschwüre und Wunden sollten durch sie geheilt werden. Auch als Gegenmittel bei Vergiftungen fand die Milch ihre Anwendung. Besonders die Eselmilch sollte säubernde Eigenschaften auf den Uterus haben ${ }^{223}$.

Die Verwendung des Essigs wurde bereits im Rezept Nr. 26 beschrieben, ebenso die Wirkung des Weines im Rezept Nr. 7. 


\section{Grundsätze der Edition}

Die Rezepte der Farfensischen Handschrift werden buchstaben-und zeilengetreu übersetzt. Abbreviaturen werden aufgelöst. Auf die Einfügung der Interpunktion wird verzichtet. Unterschiedliche Schreibweisen werden angeglichen. Rundes "s" und Langes "s" werden gleichsam als Rund "S“ wiedergegeben ${ }^{224}$.

Nicht lesbare, verderbte Stellen werden durch [...] gekennzeichnet. Bei den jeweiligen Untersuchungen wird eine mögliche Leseart diskutiert. Randnotizen werden durch „..." kenntlich gemacht. Die Seitenzahlen des Codex werden ohne Klammern auf der linken Seite gesetzt. Die Rezepte werden nach ihrer Reihenfolge von 1 bis 48, jeweils zu Beginn des Rezeptes aufgeführt.

${ }^{224}$ vgl. Hübner, 1934, S. V- IX 


\section{Edition}

$171 r$

(1)

Von gebrechen der frawen und dem chint tragen

\section{Von dem menschlichen somen}

Vnser magen versendet daz essen gar daz es do von smilczet

yn die adern daz rinnet von den adern und chumpt bis

yn die lenden daz heisen wir mannes somen do von wir alle chomen

(2)

so daz weib somen enphet

Wenn daz weib den somen enphindet enpfecht vnd ir blut darumb geet daz blut heiset menstrualis vnd wen der man mit dem weibe vmb geet So besteet es der frawen gerne daz blut ist wunder bose vnd fraysam des eiweis felden ein man daz craut durret do von die bawme schrinden do von und dorrent 
(3)

Welcher hunt des blutes isset der wirt

wuttende chein leym ist so feste den nach wasz noch under

eisen gewynnen mag mit dez blutes trophen czu geet all

czu hant oder czu mal

so die frawe nit chint treit

(4)

Welche frawe des cleinecz nicht gehaben mag die neme sa-

Ifen rauten wermut gertel und sigelbawm vnd syede daz

allez mit enander yn einem hafen der wo bedacket sey ir cleinet

(5)

Welche frawe dez cleinecz nicht gehaben mag die neme

murre und beifus saft vnd temper es mit gereben hircz-

horn vnd behulle sich gar fleissiclichen und mache j rauch

doraus secze es cunder di beine In der weile so ge-

winnet sie ire weiblicheit Czu gleicher weise sal si raute

essen vnd erlich trincken So ledigen sie die menstrua

Auch sal sie wermut saft trincken vnd di wurcz under di beine lege 
(6)

\section{dolor matricis}

Es ergeet vil dicke daz die matrix do daz chindeleyn ynne liget ersticket von dem smerbe ader von dem ubeln blute daz sie sich nicht gesawrn mag nach daz sich die frucht nit endewen noch behalden mag daz busse also Nym grune raute vnd reib die wol vnd stos an die stat Czu gleicher weise nym swebel vnd temp den mit starckem essige vnd halt die temperunge lange yn der nase vnd

\section{1v}

stos ir ein teil an die stat So wirt dir bas

\section{weibis siechtum}

Wenn daz weib den siechtum hat So geswilt sie vmb den nabel vnd welgt ir daz gelebert blut vnder den ripphen als die eier vnd geet ir yn daz heupt als ein rauch

Wiltu ir dez siechtums schier bussen nym nessel somen und seut den wol yn wein oder yn honigsem vnd gib es ir czu niessen ir wirt an der stat bas Czu gleicher weise nym raute vnd temper die mit honig daz durch geet sie vnd salbe sich auch do mit vmb die heimliche stat 
Wiltu aber schier gesunt werden So nym linsen vnd beise si i wein temper es dornach mit honig vnd nucze di artznei alle tage So wirstu gesunt

(8)

\section{von weib siechtum}

Nw sint etliche weib die haben den siechtum daz in di stat swirt wenn man sie gebraucht hat Dye sullen nemen thymiama vnd sackten die vindet man in der spicerei vnd sullen es tempern mit gense smer vnd daz vorne an salben

Nw sem ettliche weib sereg und siech yn matrixe di chumpt daz die nicht czu brauten habent Als witteben und alde tochter ader so die man lange aus sint von den weiben Dye sullen nemen salfey vnd den yn essig beisen vnd sullen in yn dem munde halden Auch sullen sie swebel yn essig beisen vnd sullen di schenbeyn do mit reiben So wirt in bas do daz weib one man ist 
(10)

So die weiber arbeit leiden so sie czu lange one man sein

daz in die matrix geswilt hilft man in nicht So werden

sie coleria Daz sol man do bey erkennen daz in di adern

dorrent vnd vnder den augen En geswilt di $[\ldots]$,fot“

ynderthalbe vnd ausserthalbe ist sie siecht En rynnen

die orn Die sullen rosen oley vnd weibes milch ne-

men die einen chnaben seuget werme die ij uber choln

vnd nym vil weiche wollen vnd welger sie dorein vnd

stos sie an die heimliche stat Hilft daz nicht So nym

galgan vnd stos den vnd mische in rosen oley vnde

streich es yn di heimliche stat

$172 r$

Welche weib chint gewynnen vnd czu brechen in der matrix daz erkenne also in ist dicke we in dem bauche vnd in ist auch als in ein spiess yn dem rucken stecke Daz busse also Nym kalck der aus chisilinge gebrant sey vnd seiffe vnd stoz daz yn einen hulczen gefese vnd mache doraus ein plaster vnd leges an di stat so wirt ir czu hant bas 


\section{Es chumet dicke daz sich geswer erheben in der matrix}

yn dem leibe do von wirt daz weib siech daz sie das duucket daz ir der leib aller erfron sey so sie an den bauch greift So duucket sie wie sie greiffe auf ein geswer daz busse also Nym bern smer vnd czu treibe daz mit einer weichen wollen und leges an die stat

Wenne dem weibe we sey yn dem matrix vnd si dunckt wie sie nyden czu samen gee oder gebinden sey daz busse also Nym hircz marck vnd ein toter von einem gebroten eie vnd mische es mit enander vnd temp ez mit rosen oley bis es dicke werde alz ein honigsam vnd lege daz plaster an die taugen stat Item magestu des nit gehaben So murren vnd reib in mit gesoten weine trick ez also warm

\section{Es erget dicke daz den weiben we wirt yn der matrix}

daz chumet do von daz di matrix vol ist des bosen

blutes Daz erchenne also die bron wieder in blotterrot

vil clein und die augen blutfar vnd gewynnen

schier do von daz starcke fieber 
Nym Czippernbawm vnd raten vnd temp die yn

wein vnd trincke daz also lange bis ez dir under stee

Ader nym eines pfarren niern vnd verseut daz yn

waser vnd temper sie denn wallendem oley vnd streiches

auf ein tuch vnd tu saffran darczu vnd legez an die stat

do du czu brachen bist under der haut so wirstu schir geheilt

Es chumet dicke daz den [...] die menstrua mude werden So nym weinreben aschen vnd binde si yn

172v

ein tuch vnd leges an di stat die menstrua rinet do von

\section{daz den weiben ir recht chume}

Nym eibisch wurcz vnd sewt die yn wasz vnd secze

dich doruber Item Ader esse raute vnd eisencraut es

chumet dir czu hant Item Ader trincke bach myuczen

saft Ader leges auf einen heisen stein vnd tu eyn

trichter ader ein fewer hutt doruber vnd laz den rauch

geen an die heimliche stat es chumet ir czu hant 


\section{Eyn anders}

Nym spiczcraut kummel habern nesseln gestosen vnd

gewollen mit gersten mel vnd tu daz warm an di stat

Ader nym ein lebentigen moltwarff vnd slach ym

den rechten fus ab vnd nym seinez blutez iij trophen

vnd trincke ez iij morgen nuchtern ez chumet dir

vnd suldestu daran sterben

\section{Aber ein anders czu verstellen}

Nym brunne cresse yn dem brunne adern vnd werme

den yn einem haffen vnd tu dorczu daz menstrua

vnd lege es auf den nabel so verstet es

Von der dicke der Weiber

Nym ij libra ${ }^{225}$ wermut vnd xxj lot cenemus daz

dritte teil viij lot kurbes daz neuwende teil iij lot

senff daz temper alles czu samen mit wasz vnd gibez

dem weibe czu trincken so wirt sie small Item

Ader nym croten craut wurczel vnd derre sie wol

\footnotetext{
${ }^{225}$ bei lb handelt es sich um die Abkürzung des Medizinalpfundes Libra, vgl. Flatow, 1932, S. 1808
} 
vnd stoz sie clein vnd trincke es mit wein oder mit wasz vnd halt ein gebetez brot fur den munt vnd fur die nase So bricht es vnden czu dem leibe auf vnd reiniget dich gar wol vnder wirdest gar reine $a b$ du ein feisten leib ader bauch hetest pro batum est

\section{Wenne den weiben die bruste swern}

So lege schoffmist also warm daruber die sere so heilen sye Item Ader nym agrimonia vnd czu stoz si wol mit aldem smere vnd $[\ldots]$ czwir aber yn dem tage bis daz bose allsampt [...] geswere Dornoch nym die wurcze vnd stoz die mit oley so lege sie auch denn $173 r$

vber So heilent sie Ab daz nicht schier wolde helffen So nym honig vnd potter vnd mische daz czu samen leges dorauf 


\section{So dem weibe die bruste geswellen}

So los wachs vnd oley czu samen vnd seut es mit fleise

vnd mache ein plaster doraus vnd leges uber die geswolst

Hilft daz nicht So nym wurgel daz craut vnd temper

es mit rosen oley vnd tu es yn ein tuchlein vnd legez of di swolst

\section{So di geswolst herte wert vnd beginnet czu swern}

Dye neme grune volkraut vnd stos daz vnd mache eyn plaster vnd leges auf vnd nym denn des saftes vnd streiches vmb die geswolst Item Ader nym grune wilde melden vnd stos sie vnd mache ein plaster doraus vnd leges off die geswolst So swern sie nymmer mer Item Ader nym maen somen vnd seut den yn regenwasz vnd leges in eyn leyne tuch vnd binde daz uber die brust drei tage 


\section{So dem weibe die milch mangelt}

vnd ir nicht kan genug gehabin

Die neme grunen venchel vnd siede yn wein ader in milch

und trincke daz dicke vnd ofte nuchtern Item Ader tricke

putter mit warm wein Item Ader esse lattich mit essig

Item Ader trincke venchel somen mit weibes milch

Wiltu wissen ab daz weib swanger sey ader nit

So gib ir met vnd milch czu trincken Beginnet sye

den bauch czu clagen So bistu sicher ader gewiss daz sie swanger

ist vnd treit Item Ader gens iren harn auf wilde pappeln

bleiben sie grune so ist sie swanger Item Ader nym eine

stelunie nadel vnd stos sie yn eine schussel vnd fach

den harn dez nachtes dorein Ist sie swanger So leget

sich der sleym underte vmb die nodel alz die hephen

Wiltu versuchen ob daz weib berhaft sey ader nit

Nym drey bon vnd lege sie yn iren harn den si nach

mitternacht gefangen hat vnd loz sie darynne legen

iij tage vnd iij nacht dornach secze sie becleiben sie 
vnd bekumen sie yn vj tagen ader in den tagen so ist ir wol czu helfen daz sie chinder treit bechomen vnd becleiben sie aber nicht So ist cheine busse nie do fur Item Also ma-

\section{$173 v$}

gestu nemen iij gersten chorner vnd loz si eyn tag vnd j nacht legen vnd secze sie dornach als die bon

\section{Wenn dem weibe ire stat beginnet czu faulen}

Nym eier vnd wol gebranten leyme ader laim auf $j$ ofen vnd churbes gleich vnd temp ez mit essig vnd las ez denn sieden bis daz wasz yngesiede vnd twinge es durch ein tuch vnd nym daz dritte teil als vil oley vnd honiges vnd mische es vnd mache czippfflein ader schublein daraus vnd stos ader scheubes darein czwir ader dreistut uuch $^{226}$ hilft ez czu faulen wunden Ader bedecke sie yn eine gefese vnd gews auff heise steine mit starcken weine vnd loz den damph wol yn sie gen

\footnotetext{
${ }^{226}$ der Kompilator setzt vor das Auch ein weiteres „A“, von der Aufnahme dieses zusätzlichen Buchstabens, wurde in der Edition abgesehen.
} 


\section{Von den weiben vnd bermuter}

Welchem weibe die bermuter swirt vnd sanfte gebiret

vnd dicke nysent so ist si gewert wenn den tragenden weiben

sich die bruste mynnern So ist sie gewiss daz die frucht

vertirbet Treit sie do czwuschen vnd ist die eine brust

mynner denn die ander sie verwirft vnd wenn daz weib

ein chint gewinet leuft ir die milch czu brusten vnde

ab daz blut czu dem tode ader vnsynn es vertirbet

Vnd als daz weib treit vnd ir die bermuter swirt ist ir

der leib dunne sie verwirft ader si stirbet ee si daz chint hot

Die meslichen leib habin die ane sucht sin die verwerffen

yn dem andern ader yn dem dritten monet

Du sal gewis sein daz die bermuter vor alle mus vol

sein von swerem somen So mag sie ir chint wol vollen tragen

Allen tragenden weiben ist die bermuter verslossen vnd den

vntragenden offen 
Welcher die milch treuft die weile sie treit siech geburt verpottet Herte brust gesunde geburt vsaget Ab sie ir aber vnderweilen mynnerten vnd ab si ir herte werden So chumet ein sere yn di brust yn die lenden yn di knye vnd yn dy augen vnd salben sie ir geburt y doch sol sie ir geburt vollen tragen

\section{Als die menstrua vil chumet}

grose sucht ir czu geet vnd als sie ir nicht chomen die $174 r$

bermuter mit manicher sere ist geweiblich vnd geldet als dem tragenden weib menstrua chumet eine gesunde geburt sal sie haben

\section{Die chalde bermuter}

Dye chalde vnd dicke bermuter haben die enphaen die vngerne die geburt Dye nasse vnd feuchte bermuter habent die verliesen den somen Dye heise vnd trucken bermuter haben di mugen nicht enphaen 
Dye ein mos dorunder begreift die gebern vnderweilen

In gleicher weise ist her dem mann czu dicke sein somen mag nicht yn die gereichen Ist er aber czu dinne so wert er czu hant vergossen ee denn er czu rechter stat chumet

Wenne alle czu flusse yn dem manne vnd nicht yn dem weibe Auch sint czwen heimliche wege yn dem mann durch den einen geet die speise durch den andern geet der somen von dem gehirne czu den orn vnd denn durch simderliche ader yn daz marck czu den lenden als ein blut So er czu den ersten von dem gehirne geet vnd wenn er also genat wirt vnd an seinen rechten weg chumet So gewynnet er czu leste weisse varbe vnd also wenn die weib chinder tragen So sullen sie sich hutten vor frost vor groszem ruffen vor vil fasten vnd vor grosem geschrey

\section{So die muter aufsteiget}

Ab die muter aufsteiget nym wermut vnd seut si in waser vnd mache sie dez selben waszs trincken 
So die muter nyder steiget darczu nym nesseln vnd seut sie yn wasz vnd lege sie uber auf die heimliche stat

Wenne daz weib arbeit czu einen chinde daz sie senfte geber

Schreib die wort an einen briff vnd gurte in ir vmb den bauch Septem dormentes maximianus machus moranonuis dromsius iohannes seraphion constanaus vnd wenne sie gebiert So heise ez ir balde ab tun ader es fure alles von ir daz sie yn ir hete yndert bey ir hete ader yn ir

\section{Eyn anders daz sie senfte gebere}

Nym vier kerczlein vnd sticke sie vmb daz weib do sie leget vnd salt auch haben weiroch vnd murre vnd golt vnd knye nyder czu ieclicher cherczen vnd sprich daz evangelium

\section{$174 v$}

In principio erat verbum vnd ein collecte dornach concede quesua omnipotens deus ut $\mathrm{N}$ vnignite filij daz tu bey den vier cherzen In einer cleinen weile gebirt sy pro batum 
(38)

\section{Daz daz weib sanfte gebere}

Die nucze vnsz frawn eis yn chaldem wasz wenn sie gebern

wil So gebirstu sanfte vnd czu hant pro batum est

Item Ader nucze hundes milch mit honig gemischt So

gebiret sye balde

\section{In welchem weibe daz chint tot ist vnd nit gebern mag}

Dye trincke weibes milch mit oley si gebirt czu hant

Item Ader si neme murre temp di mit weine vnd trincke das

also ir wirt basz vnd chumet von ir

fur $^{227}$ die bermuter

Nym die spicze von einen bockes horne vnd brenn die

vnd los rauch yn di nase gen Vnd habi den munt vnd

die augen feste czu Item Auch wart nye bessers ding

do fur denn daz chwe dreck yn dem meyen aufbrennest

vnd daz trincke wenn sie dich anstost pro batum est

Item auch wart nye bessz ding dafur denn auf gebrant

abselag aschloch wasz

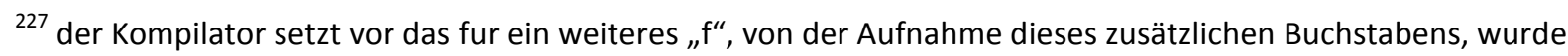
in der Edition abgesehen.
} 
Item Ader nucz saxifraga daz hilf auch den frowen gar wol

Wiltu versuchen welches weib gerne monne hat Nym ruben vnd stos die yn einen leinen tuche vnd lege es ir an di blose haut vber eine cleine weile vindestu wurmelein dorinne ab sie es gerne tut

fur die verfluchte vnchewscheit di tot sele et leib

Nym wermut nesseln gerisch gersch sadenbawm beifus

telidonia vnd raute gleich gewegen vnd stos di trinck dez saftes

Item Ader nym patonig vnd grintwurcz vnd stos dy vnd trinck daz saft So wirstu chewsche

Wiltu daz dir di bruste nicht groser werden

Nym moen somen vnd seut den in regen wasz vnd leges off ein tuchlein vnd leges dri tage uber dye bruste Item Ader nym wilde melden vnd stoz die vnd mache ein plaster doraus vnd lege es dar vber Item Ader nym veltkraut vnd leges doruber 
$175 r$

(44)

Welche [...] so sere mannes begeret von vnkeusche

wegen $[\ldots]$ sie wider essen noch trincken mag

Dye [neme] [cen]-tauriam als gros als ein phennig weget

vnd des [...] von silber als vil mit warm wasz drey

tage yedes tages einen naph vol Sye verget di bose last do von

Grenczing daz craut ist so gent gut

vngeczogen weiben die di manne so lieb haben

pulner den grenczing vnd gibes in czu nuczen yn der

speise Es sey weib ader man es geruet czu hant

(46)

Wer siech vi wirt von vncheuscher luft

lieber ader leide

Der trincke patonig mit warm wein ader mit murre

gesoten sey So wirt ym bas

Item Ader nym ertrauch vnd leges vber die brust 
(47)

So daz weib we hot an der heimlichen

an der stat daz ir hobel an dem ronde darumb werden

Dye neme tucio perporo der gar gut ist vnd nym $\mathrm{j}$ hantvol

salfey vnd seut die ij mit enander yn weis wein vnd necze

mit dem weine ir heimliche stat si wirt gesunt

(48)

ffur daz we der muter

Nym Unzen ij galgant vnd Unzen ij lorber vnd stos die ij mit enander vnd trincke dez pulners yn weis wein ein cleyn

loffel vol fur die muter wenn es ir not ist sie genist 


\section{Zusammenfassung}

Die Beurteilung der gynäkologischen Rezepte im Codex 200 aus Farfa erweist sich in vielerlei Hinsicht als schwierig:

Die innerhalb der Rezepte beschriebenen Symptome erlauben es größtenteils nicht, auf heutige gynäkologische Krankheitsbilder zu schließen, lediglich können Vermutungen aufgestellt werden. Da der Rückschluss auf heutige Krankheitsbilder weitestgehend nicht möglich war, fällt es schwer, die Sinnhaftigkeit der angewendeten Rezepturen zu überprüfen.

Die meisten angewendeten Substanzen finden heute keine Anwendung mehr, so dass zu ihren Wirksamkeiten keine aktuellen Untersuchungen vorliegen. Die Indikationen für die Verwendung verschiedener Wirkstoffe lassen sich teilweise mit der Viersäftelehre erklären. Andere Beweggründe zur Verabreichung bestimmter Substanzen sind im Volksglauben zu finden. Teilweise ist davon auszugehen, dass viele der pflanzlichen Drogen einen Placebo Effekt erzielten. Unter den Substanzen der Emmenagoga beziehungsweise Abortiva sollte jedoch eine gezielte Giftwirkung beachtet werden. Hierzu sei der Sadebaum im speziellen genannt, dieser wurde bis 1900 als illegales Abortivum benutzt ${ }^{228}$. Bei dieser Pflanze ist demnach von einer sehr effektiven Wirkung auszugehen, sonst wäre diese nicht so lange im Gebrauch geblieben. Gleichzeitig ist zu bemerken, dass bereits im Mittelalter Frauen die Möglichkeit besaßen, mit dieser Pflanze schwangerschaftsregulierende Maßnahmen zu treffen. Im Codex finden sich diese Anweisungen „versteckt“ unter den Rezepten zur Behandlung einer Amenorrhoe.

Auch der im Codex empfohlene Fenchel wird heute noch zur Milchbildung unterstützend eingesetzt.

Am Beispiel des Codex 200 erweist es sich als sehr schwierig, die mittelalterliche Medizin mit den heutigen Maßstäben zu messen. Doch zeigt sie, dass die Inhalte der jeweiligen Rezepte auf einer langen Erfahrung beruhen.

${ }^{228}$ vgl. Brøndegaard, 1964, S. 346 


\section{Literaturverzeichnis}

Brøndegaard 1964= Brøndegaard V J (1964) : Der Sadebaum als Abortivum. Sudhoffs Archiv, 48, S. 331- 351 .

Die Bibel 1985, nach der Übersetzung Martin Luthers. Deutsche Bibelgesellschaft, Stuttgart 1985.

Diepgen 1937= Diepgen P : Die Frauenheilkunde der Alten Welt. (Handbuch der Gynäkologie, 3. Auflage, 12 Band, erster Teil, Geschichte der Frauenheilkunde I), Verlag von J.F. Bergmann, München 1937.

Dioskurides 1902= Dioskurides P : Arzneimittellehre, in fünf Büchern, (Übersetzt und mit Erklärungen versehen von Prof. Dr. J. Berendes). Verlag von Ferdinand Enke, Stuttgart 1902.

Dragendorff 1967= Dragendorff G : Die Heilpflanzen der verschiedenen Völker und Zeiten. Werner Fritsch, München 1967.

Fischer- Homberger 1988= Fischer- Homberger E : Krankheit Frau. Zur Geschichte der Einbildungen. (2. Auflage ), Luchterhand Literaturverlag, Darmstadt 1988.

Flatow 1932= Flatow E : Die Medizinische Welt, Geschichte der Medizin, Anleitung zum Entziffern alter Rezepte, (Alte Medizinalgewichte und Rezepturbezeichnungen Nr.50), o. Verl., Berlin 1932, S. 1808-1809 
Hippéli/ Keil 1982= Hippéli R und Keil G : Zehn Monde Menschwerdung. Basotherm GmbH, Biberach an der Riss 1982.

Hoppe 1951 = Hoppe H A : Europäische Drogen, Band 2. Cram, de Gruyter \& Co, Hamburg 1951.

Hübner 1934= Hübner A : Grundsätze für die Herausgabe und Anweisungen zur Druckeinrichtung der Deutschen Texte des Mittelalters. In: Johannes Rothe, Das Lob der Keuschheit, hrsg. von Hans Neumann (= Deutsche Texte des Mittelalters, hrsg. von der Preussischen Akademie der Wissenschaften, 38), o. Verl., Berlin 1934, S. VIX.

HWDA 1927= Handwörterbuch des Deutschen Aberglaubens, Bächthold- Stäubli H., Band 1, 4, 5, 6 und 8 (Herausgegeben vom Verband Deutscher Vereine für Volkskunde, Abteilung I, Aberglaube), Walter de Gruyter \& CO., Vormals G.J. Göschen`sche Verlagshandlung, Berlin und Leipzig 1927- 1937.

Jerouschek 1993= Jerouschek G : Mittelalter, Antikes Erbe, weltliche Gesetzgebung und Kanonisches Recht. In: Geschichte der Abtreibung, (von der Antike bis zur Gegenwart), hrsg. Robert Jütte. Verlag C.H. Beck, München 1993.

Jühling 1900= Jühling $J$ : Die Tiere in der deutschen Volksmedizin alter und neuer Zeit, (Mit einem Anhange von Segen u. Nach den in der Kgl. öffentl. Bibliothek zu Dresden vorhandenen gedruckten und ungedruckten Quellen), Polytechnische Buchhandlung (R. Schulze), Mittweida 1900. 
Kotsch/ Keil 2008/09= Kotsch S und Keil G : Das „Erlauer Frauenbüchlein“, Untersuchungen zu einem gynäkologischen Rezeptar aus dem spätmittelalterlichen Oberungarn. Fachprosaforschung- Grenzüberschreitungen, Bd. 4/5, Deutscher Wissenschafts- Verlag (DWV), Baden- Baden 2008/09.

Kruse 1996= Kruse B J : Verborgene Heilkünste. Geschichte der Frauenmedizin im Spätmittelalter, ( Quellen und Forschungen zur Literatur- und Kulturgeschichte), Walter de Gruyter, Berlin, New York 1996.

Leibrock- Plehn 1992= Leibrock- Plehn L : Hexenkräuter oder Arznei. Die Abtreibungsmittel im 16. und 17. Jahrhundert, (Heidelberger Schriften zur Pharmazie- und Naturwissenschaftsgeschichte, Band 6). Wissenschaftliche Verlagsgesellschaft mbH, Stuttgart 1992.

Lexer 1992= Lexer M : Mittelhochdeutsches Taschenwörterbuch, 38. Auflage, S. Hirzel Verlag, Stuttgart 1992.

Lonicerus 1679= Lonicerus A : Kreuterbuch, kunstliche conterfeytunge der Bäume/ Stauden/ Hecken/ Kräuter/ Getreyd/ Gewürtze/ u. Mit eigentlicher Beschreibung/ derselben Nahmen/ in sechserley Sprachen (...). Druckts und Verlegts Matthäus Wagner, Ulm 1679.

Lothrop 2009= Lothrop H : Das Stillbuch, 33. Auflage, Kösel- Verlag, München 2009

Mattioli 1594- 1615= Mattioli P A : Kreutterbuch Deß ...Petri Andreae Matthioli...: Sampt dreyen wolgeordneten nützlichen Registern, der Kreutter Leiteinische und Teutsche Namen, und dann die Artzeneyen, darzu dieselbigen zugebrauchen , innhaltendt; Beneben gnugsamem Bericht von den Distillier und Brennöfen. 
(Einheitssachtitel: De Plantis epitome <dt.>). Zacharias Palthenius, Frankfurt, Main 1594- 1615.

Menge 1988= Menge H : Langenscheidts Grosswörterbuch Lateinisch, Teil 1, 23. Auflage, Langenscheidt, Berlin, München, Wien, Zürich 1988.

Mildenberger 1997= Mildenberger J : Anton Trutmanns Arzneibuch, Teil 2: Wörterbuch, Band 1, 2, 3, 4, 5, (Würzburger medizinhistorische Forschungen, Band 56), Königshausen und Neumann, Würzburg 1997.

Reisert 1986= Reisert R : Der siebenkammerige Uterus. Studien zur mittelalterlichen Wirkungsgeschichte und Entfaltung eines embryologischen Gebärmuttermodells, (Würzburger medizinhistorische Forschungen, Band 39). Horst Wellm Verlag, Pattensen/ Hannover 1986.

Rohland 1982= Rohland I : Das Buch von alten Schäden, Teil 2: Kommentar und Wörterverzeichnis, (Würzburger medizinhistorische Forschungen, Band 23), Horst Wellm Verlag, Pattensen/ Hannover 1982.

Schipperges 1985= Schipperges H : Der Garten der Gesundheit. Medizin im Mittelalter. Artemis Verlag, München und Zürich 1985.

Schmitz 1998= Schmitz R : Geschichte der Pharmazie, Band 1, Von den Anfängen bis zum Ausgang des Mittelalters. Govi Verlag, Pharmazeutischer Verlag $\mathrm{GmbH}$, Eschborn 1998. 
Schneider 1974= Schneider W : Lexikon zur Arzneimittelgeschichte, Band V/ 1, Pflanzliche Drogen, (Sachwörterbuch zur Geschichte der pharmazeutischen Botanik, Chemie, Mineralogie, Pharmakologie, Zoologie). Govi- Verlag GmbHPharmazeutischer Verlag, Frankfurt a. M. 1974.

Siegmund 1990= Siegmund R : Das Speyrer Frauenbüchlein, Med. Dissertation, Würzburg 1990.

Thomasset 1993= Thomasset C : Von der Natur der Frau, Mittelalter, (Geschichte der Frauen, Georges Duby, Michelle Perrot). Campus Verlag, Frankfurt/ New York 1993.

Tshisuaka 2005= Tshisuaka B I : Dreckapotheke. In: Enzyklopädie Medizingeschichte, hrsg. Gerabek W E, Haage B D, Keil G, Wegner W. Walter de Gruyter, Berlin, New York 2005, S. 322- 323

von Bingen 1957= von Bingen H : Heilkunde. Das Buch von dem Grund und Wesen und der Heilung der Krankheiten. (nach den Quellen übersetzt und erläutert von Heinrich Schipperges), Otto Müller Verlag, Salzburg 1957.

Zimmermann 1986= Zimmermann V : Rezeption und Rolle der Heilkunde in landessprachigen handschriftlichen Kompendien des Spätmittelalters. (Ars medica: Abteilung 4, Landessprachige und mittelalterliche Medizin, Band 2), Franz Steiner Verlag Wiesbaden GmbH, Stuttgart 1986. 


\section{Danksagung}

Ein ganz besonderer Dank gilt Herrn Prof. Dr. Zimmermann, der mir ermöglicht hat, an diesem interessanten Thema zu arbeiten. Während der gesamten Zeit meiner Arbeit wurde ich sehr gut betreut und beraten.

Ich danke Tamara, Sarah, Julia, Annette und Silke für das Korrekturlesen meiner Arbeit. 


\section{Lebenslauf}

Mein Name ist Sabine Zimmermann, ich wurde am 07. August 1980 in Freudenberg geboren. Ich wuchs bei meinen Eltern, Horst und Jutta Zimmermann, gemeinsam mit meinem älteren Bruder Oliver, auf. In der Zeit von 1987- 1998 absolvierte ich meine schulische Laufbahn. 1998 begann ich die Ausbildung zur Krankenschwester am St.Marienkrankenhaus in Siegen. Von 2001 bis 2006 war ich als Krankenschwester auf einer interdisziplinären Intensivstation tätig, innerhalb dieses Zeitraumes durchlief ich eine zweijährige Weiterbildung zur Fachkrankenschwester für Intensivpflege und Anästhesie. Die Tätigkeit auf der Intensivstation weckte mein besonderes Interesse an der Humanmedizin. Im Mai 2006 erhielt ich einen Studienplatz an der GeorgAugust- Universität in Göttingen. Nach dem vorklinischen Studium begann ich 2009 mit dem klinischen Teil meines Studiums. Gynäkologie und Geburtshilfe gehört zu den Fachbereichen, die mich sehr interessieren, durch Famulaturen in diesem Bereich setzte ich mich intensiver mit der Frauenheilkunde auseinander. Im Februar 2012 beginne ich mein Praktisches Jahr in Siegen. 